\title{
The RET/PTC-RAS-BRAF linear signaling cascade mediates the motile and mitogenic phenotype of thyroid cancer cells
}

\author{
Rosa Marina Melillo, ${ }^{1}$ Maria Domenica Castellone, ${ }^{1}$ Valentina Guarino, ${ }^{1}$ Valentina De Falco, ${ }^{1}$
} Anna Maria Cirafici, ${ }^{1}$ Giuliana Salvatore, ${ }^{1}$ Fiorina Caiazzo, ${ }^{1}$ Fulvio Basolo, ${ }^{2}$ Riccardo Giannini, ${ }^{2}$ Mogens Kruhoffer, ${ }^{3}$ Torben Orntoft, ${ }^{3}$ Alfredo Fusco, ${ }^{1}$ and Massimo Santoro ${ }^{1}$

\begin{abstract}
"Istituto di Endocrinologia ed Oncologia Sperimentale del CNR "G. Salvatore," Dipartimento di Biologia e Patologia Cellulare e Molecolare, University "Federico II," Naples, Italy. ${ }^{2}$ Dipartimento di Oncologia, Università di Pisa, Pisa, Italy. ${ }^{3}$ Molecular Diagnostic Laboratory,
\end{abstract} Department of Clinical Biochemistry, Aarhus University Hospital, Skejby, Aarhus, Denmark.

\begin{abstract}
In papillary thyroid carcinomas (PTCs), rearrangements of the $R E T$ receptor $(R E T / P T C)$ and activating mutations in the $B R A F$ or $R A S$ oncogenes are mutually exclusive. Here we show that the 3 proteins function along a linear oncogenic signaling cascade in which RET/PTC induces RAS-dependent BRAF activation and RAS- and BRAF-dependent ERK activation. Adoptive activation of the RET/PTC-RAS-BRAF axis induced cell proliferation and Matrigel invasion of thyroid follicular cells. Gene expression profiling revealed that the 3 oncogenes activate a common transcriptional program in thyroid cells that includes upregulation of the CXCL1 and CXCL10 chemokines, which in turn stimulate proliferation and invasion. Thus, motile and mitogenic properties are intrinsic to transformed thyroid cells and are governed by an epistatic oncogenic signaling cascade.
\end{abstract}

\section{Introduction}

Papillary thyroid carcinoma (PTC) is the most prevalent endocrine malignancy in humans (1). Four genetic lesions, at the somatic level, are associated with PTC: chromosomal alterations that affect the RET or TRKA tyrosine kinase receptors and oncogenic activation of the RAS or BRAF genes. RET encodes the tyrosine kinase receptor of growth factors belonging to the glial-derived neurotrophic factor (GDNF) family (2). RET gene rearrangements occur in up to $30 \%$ of PTCs (3). They cause the recombination of the intracellular kinase-encoding domain of RET with heterologous genes, thereby generating RET/PTC chimeric oncogenes. RET/PTC1 (the H4-RET fusion) and RET/PTC3 (the RET-fused gene-RET [RFG-RET] fusion) are the most prevalent variants. RET/PTC 3 is frequently found in radiation-associated PTC (4). The finding that $R E T / P T C$-transgenic mice develop PTC demonstrates that RET/PTC oncogenes can initiate thyroid carcinogenesis $(5,6)$. RET/PTC oncogenes are frequent in clinically silent small PTCs and are thus an early event of thyroid tumorigenesis (7). Similar rearrangements of TRKA, e.g., the high-affinity receptor for the nerve growth factor (NGF), can also be found, at a low frequency, in human PTC (8). Activating point mutations in RAS small GTPases occur in about $10 \%$ of PTCs, mainly in the follicular variant (9). Finally, point mutations in $B R A F$ are the most common genetic lesions found in PTCs (up to $50 \%$ of cases) (10). BRAF belongs to the RAF family of serine/ threonine kinases that includes c-RAF and ARAF. RAF proteins

Nonstandard abbreviations used: EST, expressed sequence tag; GDNF, glial-derived neurotrophic factor; GRO- $\alpha$, growth-related oncogene- $\alpha$; $6 \mathrm{H}, 6$ hormones; IP-10, interferon- $\gamma$-inducible protein 10; MCP-1, monocyte chemotactic protein-1; MEK, MAPK kinase; NGF, nerve growth factor; PTC, papillary thyroid carcinoma; PTX, Bordetella pertussis toxin; Q-RT-PCR, quantitative RT-PCR; RTK, receptor tyrosine kinase; siRNA, small interfering duplex RNA; SLR, signal log ratio; TG, thyroglobulin; TSH, thyrotropic hormone.

Conflict of interest: The authors have declared that no conflict of interest exists.

Citation for this article: J. Clin. Invest. 115:1068-1081 (2005).

doi:10.1172/JCI200522758 are components of the RAF-MAPK kinase-ERK (RAF-MEK-ERK) pathway, which is a highly conserved signaling module in eukaryotes. They are activated through binding to RAS in its GTP-bound state. Once activated, RAF kinases can phosphorylate MEK, which in turn phosphorylates and activates ERKs (11). As occurs in melanomas (12), a V600E substitution (formerly designated V599E), in the activation segment accounts for more than $90 \%$ of BRAF mutations in PTC $(10,13-15)$. This mutation enhances BRAF activity by disrupting the autoinhibited state of the kinase (15).

Thanks to their intrinsic kinase activity, receptor tyrosine kinases (RTKs) activate many intracellular signaling pathways. Upon binding to ligand, RTKs dimerize and autophosphorylate various cytoplasmic tyrosines. The phosphorylated tyrosines thus become binding sites for intracellular molecules containing phosphotyrosine-binding motifs, thereby initiating a diverse array of signaling pathways (16). In RET/PTC rearrangements, fusion with protein partners possessing protein-protein interaction motifs provides RET/PTC kinases with dimerizing interfaces, which results in ligand-independent autophosphorylation. The RET intracellular domain contains at least 12 autophosphorylation sites, 11 of which are maintained in RET/PTC proteins (17). Tyrosine 905 (Y905) is a binding site for Grb7/10 adaptors (18), Y1015 for phospholipase $\mathrm{C} \gamma$ (19), and Y981 for c-Src (20). Tyrosine 1062 is the binding site for several proteins, including the Shc proteins, insulin receptor substrate-1/2 (IRS-1/2), FGFR substrate 2 (FRS2), downstream of kinase $1 / 4 / 5$ (DOK1/4/5), and Enigma, which, in turn, lead to the activation of many signaling pathways $(2,21)$. Binding to She and FRS2 mediates recruitment of Grb2-SOS complexes, which thus leads to GTP exchange on RAS and RAS/ERK stimulation (22).

In human PTC, RET/PTC, RAS, and BRAF genetic alterations are mutually exclusive, which suggests that mutations at more than 1 of these sites are unlikely to provide an additional biological advantage $(10,13,14)$. This is what would be expected if the 3 proteins function in tandem along a common signaling cascade. To verify whether this is indeed the case, we examined the link 
A
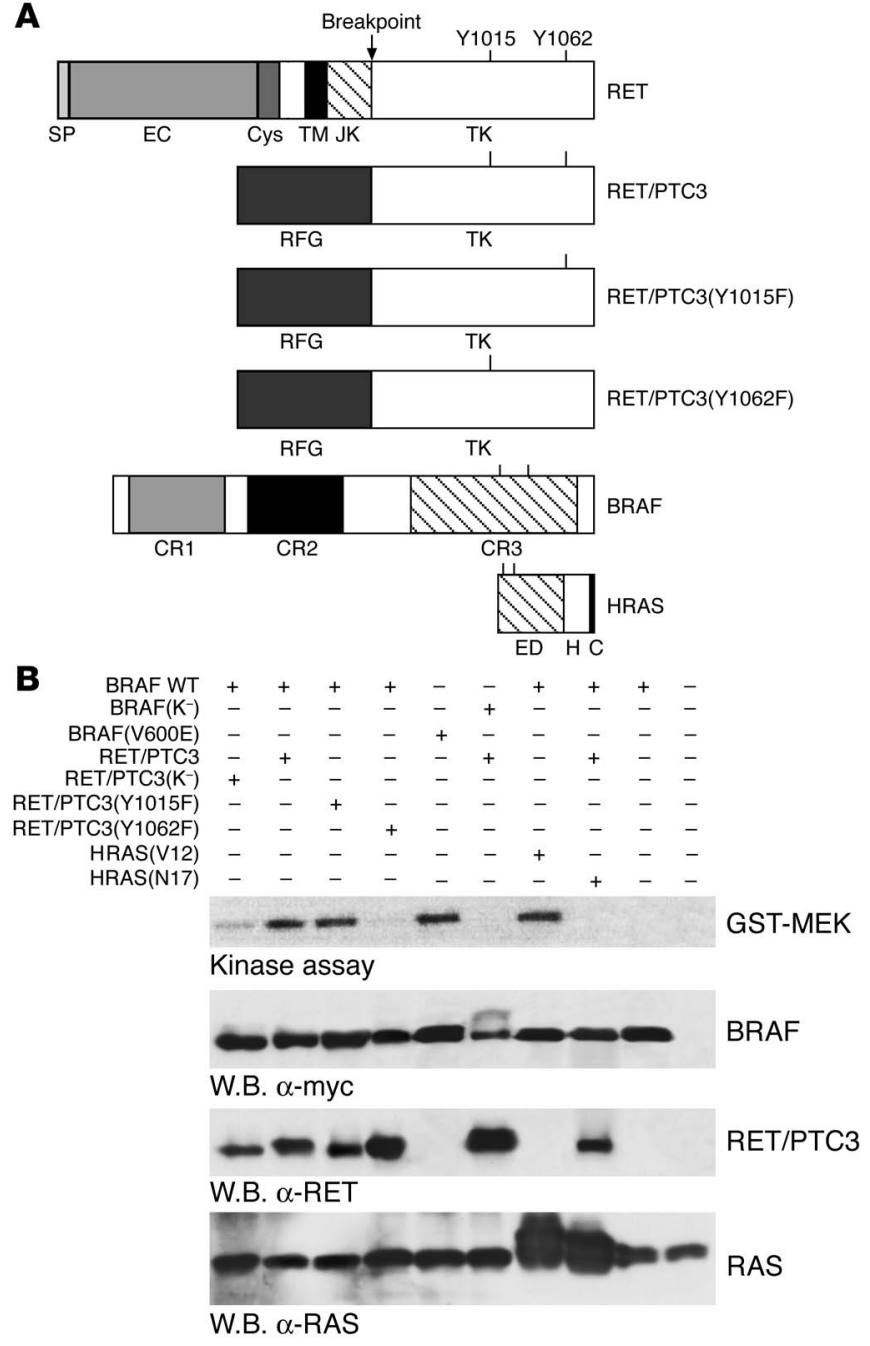

Figure 1

RET/PTC-mediated ERK activation is dependent on RAS and BRAF. (A) Schematic representation of the RET, HRAS, and BRAF constructs. The RET/PTC breakpoint and RET tyrosines 1015 and 1062 are indicated. Residues V600 and K483 are mutated to $E$ and M, respectively, in the BRAF(V600E) and BRAF(K-) plasmids. Residues $\mathrm{G} 12$ and $\mathrm{S} 17$ are mutated to $\mathrm{V}$ and $\mathrm{N}$ in the HRAS(V12) and HRAS(N17) plasmids. C, CAAX tail; CR1-3, conserved BRAF regions 1-3; Cys, cysteine-rich; EC, extracellular domain; ED, HRAS effector domain; $\mathrm{H}$, heterogeneous region; JX, juxtamembrane; SP, RET signal peptide; TK, tyrosine kinase; TM, transmembrane. (B) Protein lysates $(500 \mu \mathrm{g})$ extracted from HEK293 cells transfected with the indicated plasmids underwent immunoprecipitation with anti-tag (myc) antibody. Kinase assay was performed with GST-MEK as a substrate. BRAF and RET/PTC3 were detected by Western blotting (W.B.) with anti-myc and anti-RET antibodies, respectively. RAS expression was detected with an anti-RAS monoclonal antibody that also recognizes the endogenous protein. (C) HEK293 cells transfected with the indicated plasmids were harvested, and protein extracts were subjected to immunoblotting with anti-phospho-p44/p42 ERK (pERK) antibodies. The blot was reprobed with anti-p44/p42 antibodies for normalization. RET/PTC3 and RAS were detected by Western blotting with specific antibodies. These experiments are representative of at least 3 independent assays. (D) Transient BRAF suppression was achieved by RNA interference. Whole cell lysates were prepared 48 hours after transfection and analyzed for protein expression by Western blotting with the indicated antibodies. siRNA(SCR), scrambled siRNA.

among the 3 oncogenic proteins in a thyroid cell culture model. RET/PTC triggered the RAS-BRAF-ERK signaling cascade in a Y1062-dependent fashion. Analysis of the transcriptional profile by oligonucleotide microarrays revealed that the RET/PTC3, HRAS, and $B R A F$ oncogenes induced changes in the expression of widely
C

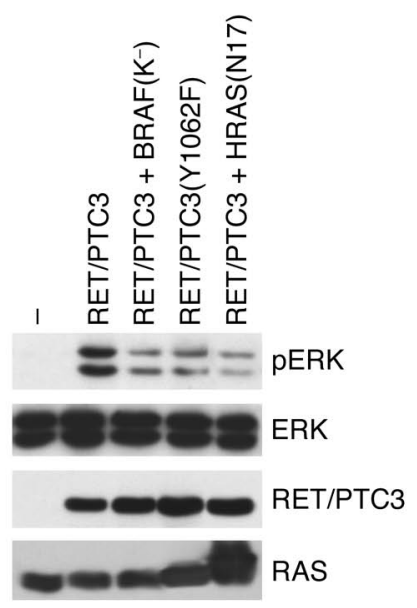

D

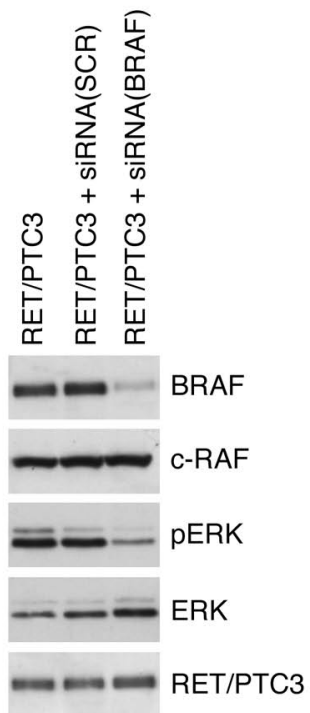

overlapping sets of genes. The RET/PTC3-RAS-BRAF axis triggered upregulation of CXC chemokines and their receptors, which in turn stimulated the mitogenic and invasive capacity of thyroid cancer cells.

\section{Results}

A biochemical cascade linking RET/PTC to the activation of $R A S, B R A F$, and ERK. We previously showed that oncogenic RET/PTC proteins activate GTP loading on RAS (23). Here, we transiently transfected HEK293 cells with myc-tagged BRAF and with the constructs shown in Figure $1 \mathrm{~A}$. We examined BRAF activity in an immunocomplex kinase assay, with the oncogenic BRAF(V600E) and the kinase-dead $\operatorname{BRAF}\left(\mathrm{K}^{-}\right)$ mutants as positive and negative controls, respectively. As shown in Figure 1B, BRAF activation was induced by the expression of the RET/PTC3 and HRAS(V12) oncogenes. Activation of BRAF depended on RET/PTC3 kinase activity and on the integrity of tyrosine 1062. Indeed, neither the kinase-dead RET/PTC3(K-) mutant nor a RET/PTC3 mutant carrying a tyrosine to phenylalanine $(\mathrm{Y} \rightarrow \mathrm{F})$ mutation at Y1062 activated BRAF. In contrast, the $\mathrm{Y} \rightarrow \mathrm{F}$ mutation at tyrosine 1015 had virtually no effect on BRAF activation. By Western blot analysis with phosphospecific anti-RET antibodies, we demonstrated that the tyrosine 1062 substitution does not affect RET/PTC3 autophosphorylation levels overall or Y1015 and Y905 phosphorylation (Supplemental Figure 1; supplemental material available online with this article; doi:10.1172/ JCI200522758DS1). Expression of the dominant-interfering HRAS(N17) mutant blocked RET/PTC3-mediated BRAF activation, which indicates that in this context, BRAF activation requires RAS (Figure 1B). We explored whether the RET/PTC3(Y1062)RAS-BRAF cascade resulted in ERK1/2 stimulation. RET/PTC3 


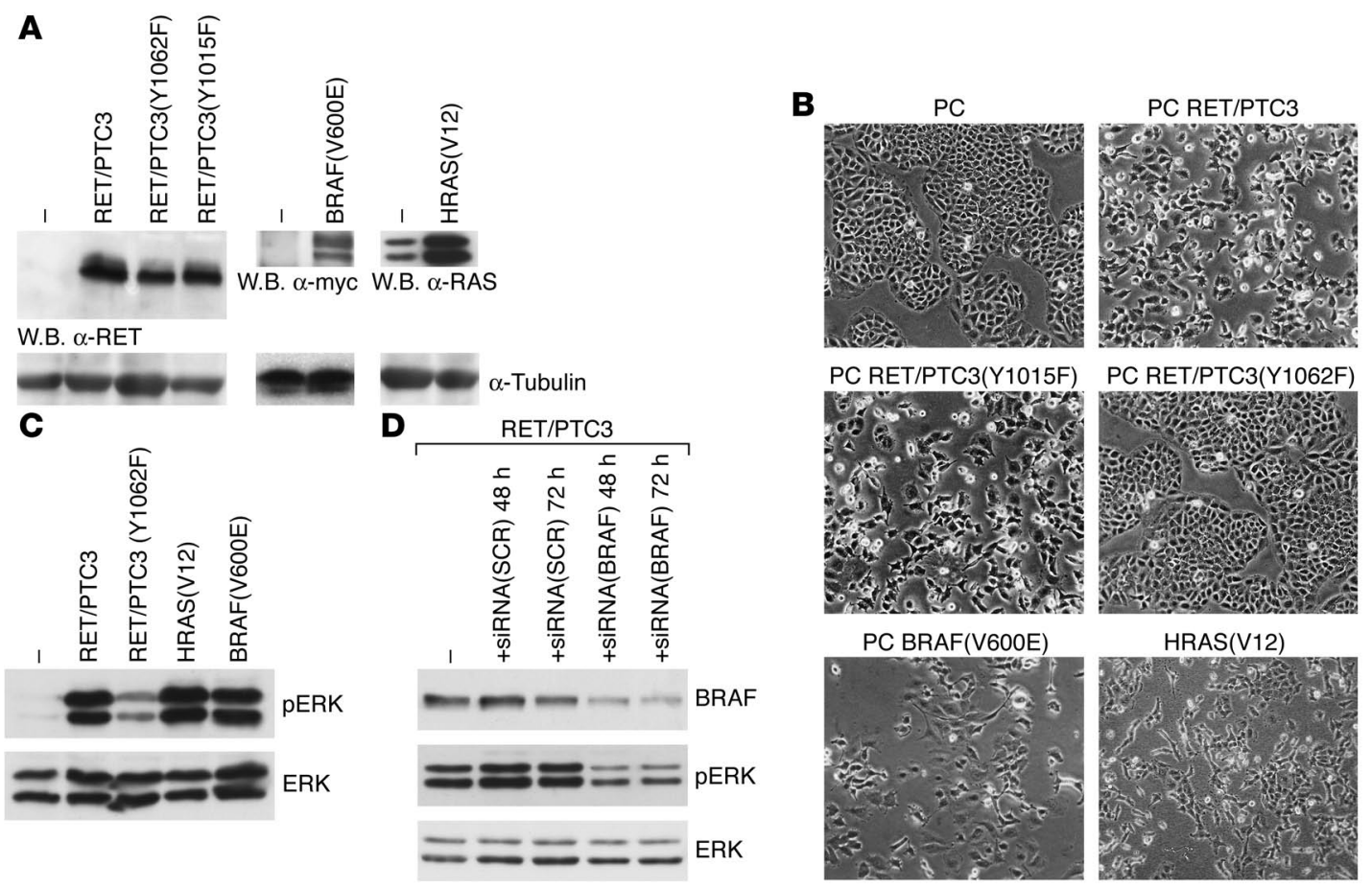

\section{Figure 2}

Generation of thyroid cell cultures. (A) Protein lysates $(50 \mu \mathrm{g})$ extracted from the indicated cell lines underwent Western blotting with anti-RET, -tag (myc), or -RAS antibodies. Equal protein loading was ascertained by anti-tubulin immunoblot. (B) Mass populations of PC cells transfected with the indicated plasmids were photographed using a phase-contrast light microscope (magnification, $\times 150)$. RET/PTC3-, RET/PTC3(Y1015F)-, BRAF(V600E)-, and HRAS(V12)-expressing cells displayed a transformed morphology, whereas RET/PTC3(Y1062F)-expressing cells were virtually indistinguishable from parental cells. (C) Protein extracts from the indicated cell lines were subjected to immunoblotting with anti-phosphop44/42 ERK antibodies. The blot was reprobed with anti-p44/42 antibodies for normalization. (D) BRAF targeting by siRNA but not by scrambled siRNA induced BRAF downregulation and ERK inhibition, as shown by Western blotting with specific antibodies.

stimulated ERK activation, as revealed by immunoblot with a phospho-specific antibody (Figure 1C). This activation did not depend on Y1015 (data not shown); instead, it was dependent on the integrity of Y1062 and on the activity of RAS and BRAF, being obstructed by the expression of HRAS(N17) and BRAF $\left(\mathrm{K}^{-}\right)$ dominant negative mutants (Figure $1 \mathrm{C})$. The $\mathrm{BRAF}\left(\mathrm{K}^{-}\right)$dominant negative mutant probably acts as a pan-RAF inhibitor in that it blocks the activity of the various RAF proteins. To specifically block BRAF, we used small interfering duplex RNA (siRNA) oligonucleotides that target endogenous BRAF. This duplex affected only BRAF and no other member of the RAF family (Figure 1D and data not shown). Silencing of BRAF in RET/PTC3transfected HEK293 cells inhibited ERK activation. This effect was specific, since a control scrambled siRNA did not alter ERK activity (Figure 1D). Taken together, these findings demonstrate that phosphorylation of RET/PTC tyrosine 1062 triggers RASdependent stimulation of BRAF signaling.

Generation of the cellular model system. PC Cl 3 (referred to hereafter as PC) is a continuous line of follicular thyroid cells, derived from Fischer rats, that constitutes a model system with which to study differentiation and growth regulation in an epithelial thyroid cell setting. PC cells express the thyroid-specific gene thyroglobulin (TG) and the thyroid-specific transcription factors TTF-1 and PAX-8. They require a mixture of 6 hormones $(6 \mathrm{H})$, including thyrotropic hormone (TSH) for proliferation (24). RET/PTC1 expression causes hormone-independent proliferation of PC cells
(25-27); hence, the system lends itself to the study of RET/PTCmediated effects. We generated marker-selected mass populations of several PC cell clones stably transfected with RET/PTC3, HRAS(V12), or BRAF(V600E). The corresponding proteins were correctly synthesized (Figure 2A); ERK activity was stimulated by each of the 3 oncoproteins (Figure 2C). The oncogene-transfected cell populations showed a similar, albeit not identical, morphologically transformed phenotype, i.e., spindle-shaped and refractile cells scattered on the surface of the culture dish (Figure 2B). RET/PTC3, HRAS(V12), and BRAF(V600E) oncogenes abolished the dependency of PC cell proliferation on the $6 \mathrm{H}$ (Figure $3 \mathrm{~A}$ ). Efficiency of colony formation was $35 \% \pm 5 \%$ in the case of HRAS(V12), perhaps due to the reported proapoptotic role of acute overexpression of the oncoproteins $(23,27)$. Oncogenetransfected cells maintained increased levels of $\mathrm{G}_{1}$ cyclin D1 under conditions of $6 \mathrm{H}$ deprivation (Figure $3 \mathrm{~A}$, inset). Moreover, oncogene-transfected PC cells exerted an invasive phenotype through Matrigel (Figure 3B) and lost the differentiated phenotype (data not shown). In the case of RET/PTC3, all these features, as well as BRAF-ERK activation, depended on tyrosine 1062 but not on tyrosine 1015 (Figures 2 and 3). Since tyrosine 1062 is a multi-docking site in RET and is required to activate several signaling pathways, we used RNA interference to specifically downregulate BRAF in PC cells transfected with RET/PTC3 (PC RET/PTC3 cells). As shown in Figure 2D, transfection with BRAF siRNA, but not with the control scrambled siRNA, diminished BRAF protein levels. ERK 
A
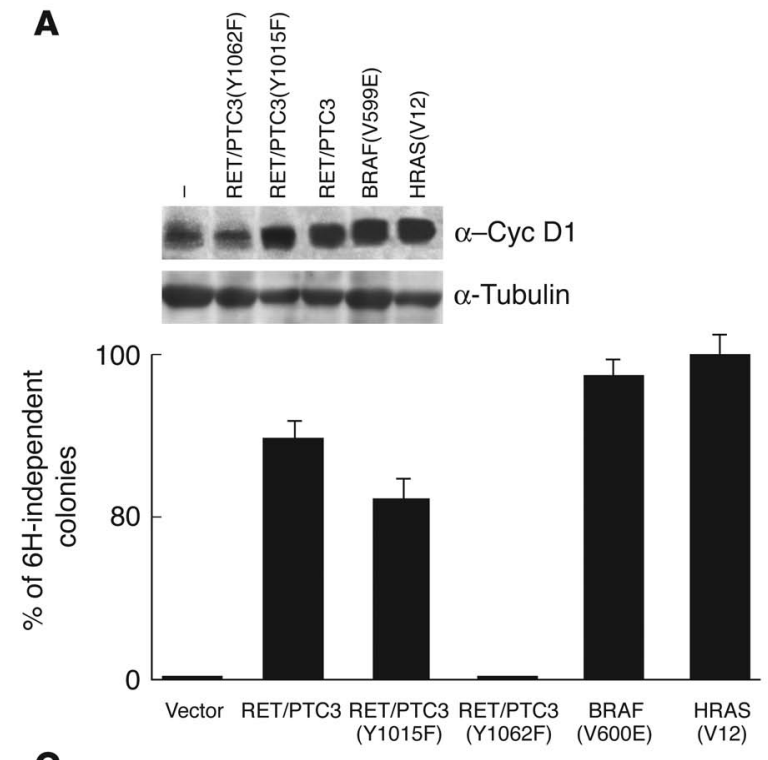

C

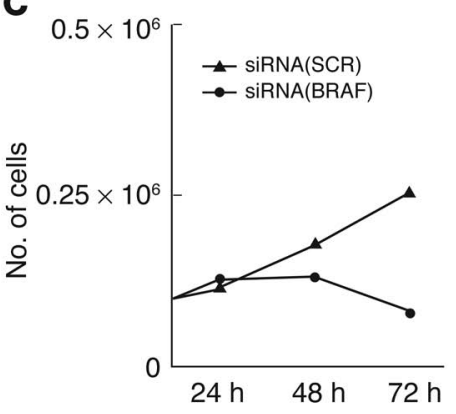

B
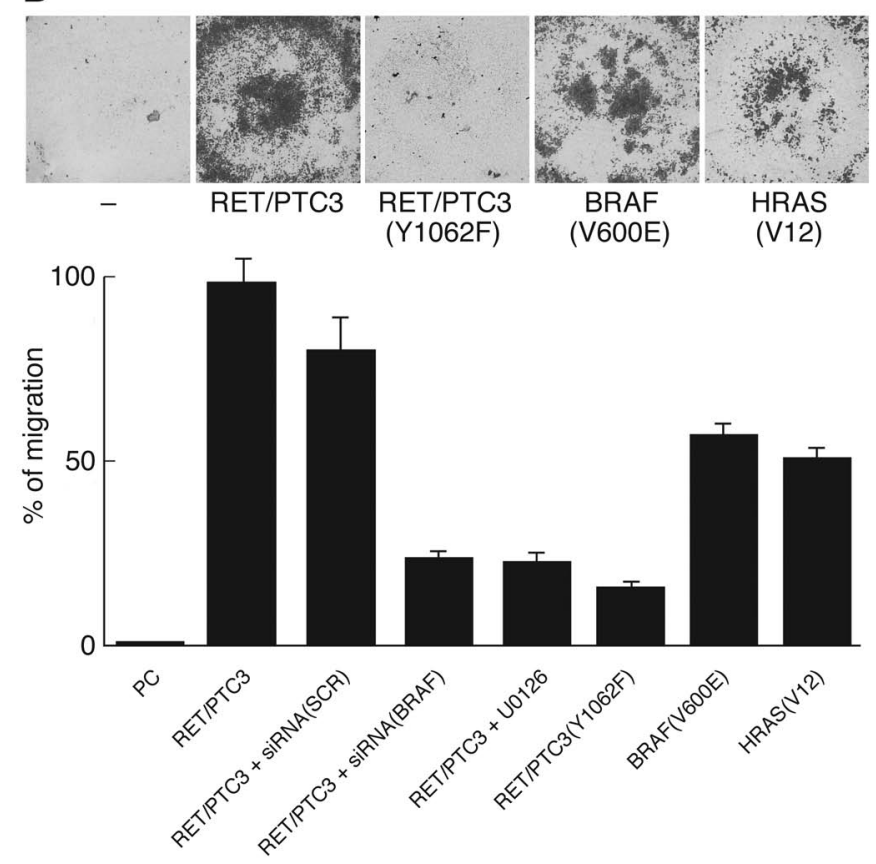

Figure 3

The transformed phenotype of RET/PTC3 thyroid cells requires the integrity of the Y1062-RAS-BRAF-ERK pathway. (A) PC cells were transfected with the indicated plasmids or the empty vector and either selected in neomycin-containing medium or left in the absence of $6 \mathrm{H}$. Three weeks later, colonies were stained with crystal violet and counted. The ratio of neomycin-resistant clones to $6 \mathrm{H}$-independent colonies was calculated. The results of 3 independent experiments performed in duplicate $\pm \mathrm{SD}$ are reported [the number of $6 \mathrm{H}$-independent colonies induced by HRAS(V12) was set at 100]. Inset: Protein lysates (50 $\mu \mathrm{g})$ underwent Western blotting with the indicated antibodies. cyc D1, cyclin D1. (B) Matrigel invasion of parental and transformed PC cells. Where indicated, in PC RET/PTC3 cells, suppression of endogenous BRAF was obtained by transfection of RNA interference against BRAF, and ERK inhibition was achieved by U0126 treatment. Cells were seeded in the upper chamber of $8-\mu \mathrm{M}$-pore transwells and incubated for 24 hours. Thereafter, filters were fixed and stained. The upper surface was wiped clean and cells on the lower surface photographed (top) and then solubilized. Absorbance at $570 \mathrm{~nm}$ was measured with a microplate reader. Cell migration is expressed as percentage with respect to RET/PTC 3 cells, whose migration was arbitrarily set at 100 . Each column represents the average \pm SD of 3 independent experiments (bottom). (C) Suppression of endogenous BRAF in PC RET/PTC3 cells was obtained by transfection of RNA interference against BRAF. Cells were counted at different time points, and the average results of 3 independent experiments are reported.

activity was downregulated by BRAF knockdown (Figure 2D). Importantly, the transient silencing of BRAF inhibited the invasive activity and growth of PC RET/PTC3 cells, whereas the negative control siRNA was ineffective (Figure 3, B and C). Downregulation of ERK activity achieved with U0126, a specific MEK inhibitor, also inhibited PC RET/PTC3 proliferation (data not shown) and Matrigel invasion (Figure $3 \mathrm{~B}$ ).

A gene expression signature of the RET/PTC3-RAS-BRAF axis in thyroid cells. We explored gene expression changes after PC cell transfection with RET/PTC3, HRAS(V12), or BRAF(V600E). We also used cells expressing RET/PTC3(Y1062F) and RET/PTC3(Y1015F) mutants. To study the expression profiles, we used oligonucleotide-based DNA microarrays (GeneChip; Affymetrix) containing oligonucleotide probe pairs corresponding to more than 16,000 known genes and expressed sequence tag (EST) clusters. RNA was extracted from mass populations of cells (pool no. 3 for each oncogene), converted into fluorescently labeled complementary RNA (cRNA), and hybridized to arrays. Each chip was analyzed with Affymetrix Microarray Suite 5.0 Software to generate raw expression data. Fold change (signal log ratio [SLR]) was calculated by pairwise comparison of probe pairs from the experiment (cells expressing the different oncogenes) with baseline (untransfected parental cells). In order to sort the genes with changes in mRNA abundance in response to the different oncogenes, we defined a filter query that "passed" only data sets that were denoted "increased" or "decreased" by the software and that showed a fold change of 4 or more (SLR $\geq 2$ for upregulated genes; SLR $\leq-2$ for downregulated genes). The entire data set is available as Supplemental Table 1.

We first examined genes whose expression was expected to be modified by thyroid cell transformation. Consistent with the 

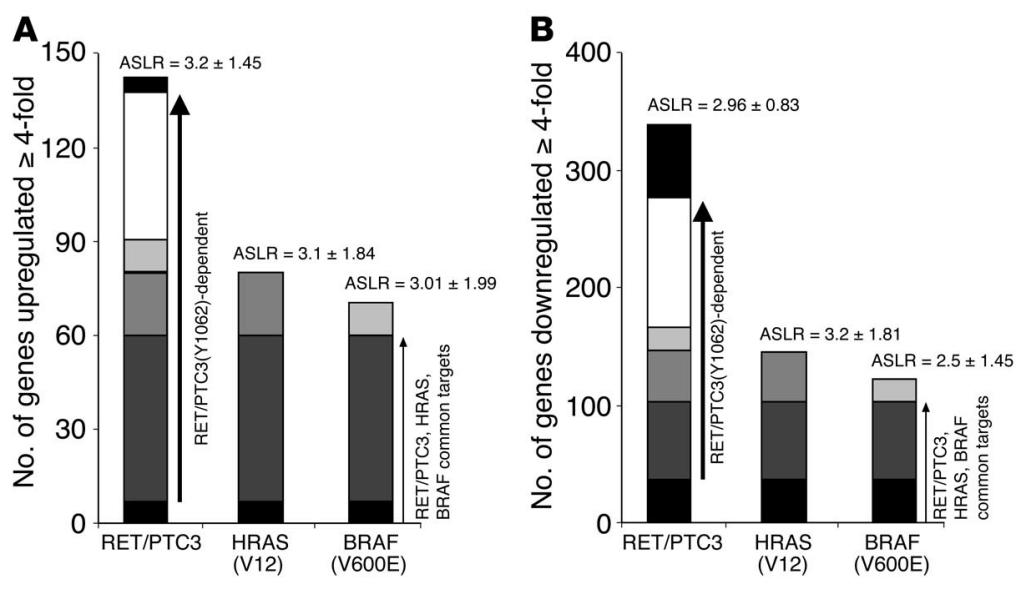

RET/PTC3(Y1062)-independent $\square$ RET/PTC3-specific $\square$ RET/PTC3, BRAF common targets

\section{Figure 4}

Graphic representation of the gene expression changes (fold change of at least 4) in RET/PTC3, BRAF(V600E), and HRAS(V12) cells versus baseline (PC): upregulated genes (A) and downregulated genes (B). The numbers of upregulated and downregulated genes are represented on the $y$ axis. Thick arrows indicate the Y1062dependent genes; thin arrows indicate the targets common to RET/PTC3, BRAF(V599E), and HRAS(V12). The different groups of genes are highlighted. Average SLRs (ASLR) are indicated. above-described cell phenotype, microarray screening demonstrated upregulation of $\mathrm{G}_{1}$ cyclins (D and E cyclins) and downregulation of thyroid differentiation markers (including TG, TTF-1, and PAX-8) (Supplemental Table 1). Then we examined the global expression profile. Some genes were regulated by only 1 or 2 oncoproteins. However, cross-comparison of the results revealed a group of sequences that were regulated in a similar fashion in RET/PTC3, HRAS(V12), and BRAF(V600E) cells (Figure 4 and Supplemental Figures 2 and 3). Whereas the former probably reflect the specific biological activity of each oncoprotein, the common targets represent a transcriptional signature of the expression of the 3 oncogenes in thyrocytes. Of the 786 oligonucleotide probe pairs whose expression was increased in RET/PTC3 cells (Supplemental Figure 2A), 146 showed an SLR of 2 or more (average SLR, 3.2; Figure 4A). Tyrosine 1062 played a pivotal role in these expression changes. In fact, upregulation of most sequences (131 of 146, 90\%) required the integrity of Y1062; the remaining 15 sequences were still induced after the Y1062F mutation, albeit to a lesser extent (average SLR, 1.8) (Figure 4A). In contrast, upregulation of a few of them (less than 15\%) depended on tyrosine 1015; most of them depended also on Y1062 (data not shown). Many of the sequences induced by RET/PTC3 were also induced by HRAS(V12) (80 of 146, 54\%) and BRAF(V600E) (70 of $146,48 \%$ ) cells with a similar average SLR (Figure 4A). Overall, 60 (41\%) of the oligonucleotide probe pairs induced in RET/PTC3 cells were induced in both HRAS(V12) and BRAF(V600E) cells, and as many as $87 \%$ (52 of 60) were Y1062 dependent (Figure 4A). These upregulated oligonucleotide probe pairs corresponded to the 32 genes and 19 ESTs listed in Table 1. Similarly, sorting of HRAS(V12)and BRAF(V600E)-induced sequences showed that RET/PTC3 cells upregulated a large set of them in a Y1062-dependent fashion (Supplemental Figure 3). Of the 2,517 oligonucleotide probe pairs whose expression was decreased in RET/PTC3 cells (Supplemental Figure 2B), 338 were downregulated 4-fold or more (average SLR, -2.96). Again, a large fraction of these sequences was also downregulated in HRAS(V12) (148 of 338, 44\%; average SLR, 3.2 ) and in BRAF(V600E) (121 of 338, 36\%; average SLR, 2.5) cells (Figure 4B). Overall, 104 (31\%) sequences were downregulated by all 3 oncogenes, with 66 of them (64\%) being dependent on the integrity of Y1062 (Figure 4B). These downregulated oligonucleotide probe pairs corresponded to the 50 genes and 41 ESTs listed in Table 2.
Validation of the expression data in cultured cells and in human PTCs. We used quantitative RT-PCR (Q-RT-PCR) to evaluate the expression of 50 genes ( 31 of the 32 upregulated and 19 of the 50 downregulated genes listed in Tables 1 and 2). To verify that gene expression changes were not due to a clonal effect during selection, we analyzed gene expression levels in the mass population (pool no. 3) and in 2 individual clones $(\mathrm{Cl} 1$ and $\mathrm{Cl} 2)$ for each cell line. We then statistically analyzed the expression changes induced by each oncogene. In most cases (37 of the 50 genes), RET/PTC3, HRAS(V12), and $\mathrm{BRAF}(\mathrm{V} 600 \mathrm{E})$ activity altered the expression of a particular gene identified by the microarray method. The results of these experiments and the relative statistical analysis are reported in Table 3. In 5 cases (marked in bold in the table), Q-RT-PCR data were not statistically significant $(P>0.05)$; however, in these cases, expression changes showed a trend consistent with that in microarray data.

All the genes examined were affected by the Y1062F mutation, their expression changes being negligible in PC RET/PTC(Y1062F) cells (Tables 1 and 2 and data not shown). Moreover, using PC cells transfected by RET/PTC1, another RET/PTC variant, we also demonstrated that gene changes were not restricted to the isoform (RET/PTC3) used in the array screen (data not shown). To determine whether activation of the RAS-BRAF-ERK pathway was required for gene expression regulation induced by RET/PTC3, we used Q-RT-PCR to measure the expression levels of the 37 genes listed in Table 3 in RET/PTC3 cells in which the pathway was transiently obstructed, either by BRAF siRNA or by the MEK inhibitor U0126. As shown in Table 4, expression of 22 of the 37 genes was affected by both BRAF silencing and U0126 treatment. With the sole exception of the Ca2 gene, which was obstructed by U0126 but not by BRAF silencing, there was complete concordance between the results obtained with siRNA and U0126 treatment (Table 4). Scrambled siRNA, used as a negative control, did not affect expression levels (Table 4). These findings support the notion that the BRAF-MEK cascade is essential for the gene expression signature of RET/PTC-transformed cells, but they do not necessarily prove that it is also sufficient. It might well be that additional pathways (perhaps triggered by the same Y1062) contribute to the establishment of the phenotype.

We selected 4 genes upregulated more than 4 -fold and 3 genes (Arpc1b, CD44, RUNX1) upregulated less than 4-fold in the microarray screen. Using Q-RT-PCR, we compared the expression levels of these 
Table 1

Genes upregulated 4-fold or more in RET/PTC3 cells ${ }^{A}$

\begin{tabular}{|c|c|c|c|c|c|}
\hline Gene & UniGene no. & RET/PTC3 & Y1062F & HRAS & BRAF \\
\hline \multicolumn{6}{|c|}{ Signaling/growth } \\
\hline$A d m^{B}$ & Rn. 10232 & 3.6 & NC & 4.1 & 3.6 \\
\hline Dusp6 $6^{\mathrm{B}}$ & Rn. 4313 & 3.3 & $\mathrm{D}$ & 2.5 & 3 \\
\hline $\operatorname{Itga1} 1 \mathrm{~B}$ & Rn. 91044 & 2.9 & NC & 3.7 & 3.2 \\
\hline Marks C & Rn. 9560 & 2.4 & NC & 2.1 & 2.4 \\
\hline $\operatorname{lgf} 2 r^{C}$ & Rn. 270 & 3 & $\mathrm{D}$ & 3.6 & 3.7 \\
\hline$S g k^{\mathrm{B}}$ & Rn. 4636 & 2 & $D$ & 1.4 & 3.1 \\
\hline PI4K2BB & Rn. 21189 & 2.6 & NC & 2 & 0.8 \\
\hline \multicolumn{6}{|l|}{ Transcription } \\
\hline Fh/2 ${ }^{\mathrm{B}}$ & Rn. 3849 & 2.7 & NC & 3.5 & 2.8 \\
\hline CITED2 ${ }^{\mathrm{B}}$ & Rn.31765 & 2.65 & NC & 2.45 & 2.65 \\
\hline IRF7-like C & Rn. 6246 & 2.1 & $\mathrm{D}$ & 2.3 & 2.7 \\
\hline \multicolumn{6}{|c|}{ Inflammation/immunity } \\
\hline $\operatorname{Spp} 1^{\mathrm{B}}$ & Rn. 8871 & 6.1 & NC & 7.3 & 2.3 \\
\hline$C C L 2^{\mathrm{B}}$ & Rn. 4772 & 7 & NC & 6.15 & 6.5 \\
\hline$C X C L 1^{B}$ & Rn. 10907 & 5.3 & NC & 7.3 & 6.1 \\
\hline \multicolumn{6}{|l|}{ Proteolysis } \\
\hline Mmp13 В & Rn 10997 & 9.4 & NC & 8.9 & 9.6 \\
\hline Мmp10 В & Rn. 9946 & 10 & NC & 8.6 & 10 \\
\hline Mmp12В & Rn. 33193 & 7.8 & NC & 5.1 & 6.7 \\
\hline Mmp3 & Rn. 32086 & 7.5 & NC & 5.2 & 6.9 \\
\hline USP18-like & Rn. 4165 & 2.7 & NC & 4 & 2.7 \\
\hline \multicolumn{6}{|l|}{ Metabolism } \\
\hline GSTm2C & Rn. 625 & 2.3 & NC & 0.7 & 3 \\
\hline$T h^{\mathrm{B}}$ & Rn. 11082 & 2 & NC & 4.8 & 1.6 \\
\hline$F d p s^{C}$ & Rn. 2622 & 2.2 & NC & 1.9 & 0.4 \\
\hline $\mathrm{Ca} 2^{\mathrm{B}}$ & Rn. 26083 & 4.9 & NC & 6.6 & 5.7 \\
\hline$D d b i^{C}$ & Rn. 3285 & 2.3 & 1.5 & 1.3 & 1.3 \\
\hline$L d l r^{C}$ & Rn. 10483 & 3 & 1 & 2.7 & 0.9 \\
\hline \multicolumn{6}{|c|}{ Structure/adhesion } \\
\hline $\operatorname{Lgals}^{\mathrm{B}}$ & Rn. 764 & 2.7 & $\mathrm{D}$ & 2.1 & 1.7 \\
\hline Col1a1 & Rn. 2953 & 6.5 & NC & 1.4 & 4.9 \\
\hline$T m s b 4 x^{\mathrm{B}}$ & Rn. 2605 & 3.5 & $\mathrm{D}$ & 2.4 & 2.3 \\
\hline $\operatorname{Vim}^{\mathrm{C}}$ & Rn. 2710 & 2 & $\mathrm{D}$ & 0.5 & 0.6 \\
\hline Lgals $1^{\mathrm{B}}$ & Rn. 57 & 2.5 & NC & 1.9 & 1.2 \\
\hline Dysf2-like & Rn. 22869 & 2.9 & 2.9 & 3.5 & 2.3 \\
\hline \multicolumn{6}{|c|}{ Calcium binding } \\
\hline$S 100 A 4^{B}$ & Rn. 504 & 5 & NC & 3 & 3.6 \\
\hline$S 100 A 6^{B}$ & Rn. 3233 & 2.9 & $\mathrm{D}$ & 3 & 3 \\
\hline \multicolumn{6}{|l|}{ EST } \\
\hline AA849365 & Rn. 22831 & 2.9 & 2.9 & 3.5 & 2.3 \\
\hline AA851210 & Rn. 1392 & 2.4 & NC & 2.3 & 1.5 \\
\hline AA866419 & Rn. 3099 & 2 & NC & 1.8 & 1.2 \\
\hline AA875032 & Rn. 3212 & 2.1 & $\mathrm{D}$ & 1.2 & 0.7 \\
\hline AA900974 & & 2 & D & 1.9 & 1.5 \\
\hline AA926129 & Rn. 34404 & 2.6 & $\mathrm{D}$ & 1.1 & 1 \\
\hline AA944463 & Rn. 7736 & 2.2 & NC & 3.9 & 3.9 \\
\hline AA945591 & Rn. 1414 & 2.2 & 0.6 & 2.5 & 1.2 \\
\hline AA957167 & & 3.2 & NC & 1.4 & 2.3 \\
\hline AA998535 & & 2.6 & 1.8 & 2.6 & 1.4 \\
\hline Al010910 & Rn. 17645 & 39 & NC & 2.5 & 2.2 \\
\hline Al013157 & Rn. 98226 & 2.1 & 2.6 & 1.9 & 2.2 \\
\hline Al013888 & Rn. 6715 & 2.6 & 0.9 & 2.5 & 2.2 \\
\hline Al029439 & Rn. 18227 & 2.4 & NC & 2.3 & 2.3 \\
\hline Al029829 & Rn. 18332 & 2.1 & NC & 2.3 & 1.6 \\
\hline Al044253 & Rn. 15847 & 3.2 & NC & 3.3 & 3.6 \\
\hline Al059223 & Rn. 19102 & 6.4 & NC & 2.7 & 7.2 \\
\hline Al059519 & Rn. 19198 & 2.4 & NC & 2 & 0.8 \\
\hline Al059622 & Rn. 105857 & 3.1 & 3.3 & 1.8 & 3.1 \\
\hline
\end{tabular}

AThe genes induced in RET/PTC3 cells 4-fold or more and also upregulated in HRAS and BRAF cells are listed. BTargets whose upregulation was confirmed by RT-PCR. ${ }^{C}$ Targets whose upregulation was not confirmed. Targets not further studied by PCR are unmarked. NC, not changed; D, decreased; Rn., rattus norvegicus unigene cluster. genes in a set of primary human PTC tissue specimens $(n=13)$ characterized for oncogene activation (BRAF or RET/PTC) (28) to those in 5 samples of normal thyroid tissue obtained from different donors. Successfully amplified samples are reported in Figure 5A. All 7 analyzed genes were found to be upregulated in most of the tumor samples, and for 5 of them, $P$ was 0.05 or less. We then examined genes coding for the chemokines CXCL1/growth-related oncogene- $\alpha$ (CXCL1/GRO- $\alpha$ ) and CXCL10/interferon- $\gamma$-inducible protein 10 (CXCL10/IP-10), using a larger set of tumor samples $(n=18)$ in this case. Both chemokine-encoding genes were significantly upregulated in PTC samples with respect to normal thyroid tissue (Figure 5B).

Autocrine loops that sustain mitogenesis and motility of thyroid cancer cells. Chemokines are small chemotactic cytokines that are subdivided into 2 main families ( $\alpha$ or CXC and $\beta$ or CC chemokines) on the basis of the relative position of cysteine residues (29). Chemokines bind to 7 -transmembrane receptors present in the cell surface that are coupled to $G \alpha_{i}$ class $G$ proteins and are therefore inhibited by Bordetella pertussis toxin (PTX). Chemokine receptor activation leads to a cascade of cellular events: generation of diacylglycerol and inositol triphosphate, release of intracellular calcium, inhibition of adenylyl cyclase, and activation of several signaling proteins, including JAK/STATs, PKC, phospholipase C, PI3K, and small GTPases of the Ras and Rho families. This cascade results in activation of AKT and ERK and in cell polarization, adhesion, and migration $(30,31)$.

According to the microarray screen, CXCL1/GRO- $\alpha$ and CCL2/ monocyte chemotactic protein-1 (CCL2/MCP-1) were upregulated more than 4-fold in transformed thyrocytes (Table 1). CXCL10/IP-10 was also upregulated, albeit to a lesser extent (Supplemental Table 1). CCL2 is known to be abundantly produced in human PTC (32). However, its receptor, CCR7, was not detectable in thyroid follicular cells (R.M. Melillo et al., unpublished observations). On the other hand, our Q-RT-PCR data demonstrated that CXCL1 and CXCL10 were upregulated in human PTCs (Figure 5B). According to the microarray data, CXCR2 (the CXCL1 receptor) and CXCR3 (the CXCL10 receptor) were expressed in parental and transformed PC cells (Supplemental Table 1).

First, an ELISA assay demonstrated that CXCL1 and CXCL10 were more abundantly secreted by human PTC cell lines spontaneously carrying the RET/PTC1 rearrangement (TPC1, FB2, BHP2-7) or the BRAF(V600E) mutation (BCPAP, BHP5-16) than by $\mathrm{P} 5$, a primary culture of normal human thyroid follicular cells (Figure 6A). Moreover, the mRNA for CXCR2 and CXCR3 was upregulated in all the PTC cell lines compared with normal P5 cells (Figure 6B). Accordingly, both receptors were found to be expressed on the cell surface of the 5 PTC cell lines by flow cytometric analysis (Figure 6C and data not shown).

Treatment of TPC1 cells with BRAF siRNA caused a decrease in endogenous BRAF levels and a parallel reduction of ERK activity (Figure 6D). In parallel, BRAF siRNA, but not scrambled siRNA, remarkably attenuated CXCL1 and CXCL10 chemokine secretion (Figure 6E).

TPC 1 cells were stimulated with recombinant CXCL1 or CXCL10; cells were harvested at different time points, and activation of ERK and AKT was analyzed with phospho-specific antibodies. Both chemokines stimulated potent ERK and AKT phosphorylation starting as early as 1 minute after treatment; ERK activation occurred earlier than AKT activation (Figure 7A). To measure DNA synthesis, we counted BrdU-positive cells upon a 1-hour BrdU pulse. The average results of 3 independent experiments are reported in 
Table 2

Genes downregulated 4-fold or more in PC RET/PTC3 cells ${ }^{A}$

SLR

Gene

\section{Cell cycle}

Gas $6^{\mathrm{B}}$

Transcription

Nr4a1c

$\mathrm{Crem}^{\mathrm{B}}$

Hhex ${ }^{\mathrm{B}}$

Nr4a3c

IRF8 ${ }^{B}$

Thyroid differentiation

\begin{tabular}{|c|c|c|c|c|c|}
\hline Titf1 & Rn. 34265 & 3.4 & NC & 3.3 & 1.1 \\
\hline Tpo & Rn. 91199 & 3.8 & NC & 3.8 & 4.5 \\
\hline Tshr & Rn. 87913 & 2 & NC & 4 & 2.2 \\
\hline $\mathrm{Tg}$ & Rn. 10429 & 4.95 & 1 & 6.8 & 4.82 \\
\hline Dio1 & Rn. 87549 & 3.6 & NC & 2.5 & 3.15 \\
\hline $\operatorname{Trg}$ & Rn. 10431 & 2.9 & NC & 2.6 & 1.2 \\
\hline Slc5a5 & Rn. 10505 & 2.5 & 1 & 3.4 & 2.5 \\
\hline \multicolumn{6}{|c|}{ Metabolism } \\
\hline Kcnk3 & Rn. 80679 & 2.9 & 2.5 & 3.8 & 3.3 \\
\hline Decr1 & Rn. 2854 & 2 & 0.6 & 1.9 & 1 \\
\hline Ephx1 & Rn. 3603 & 2.5 & 1.3 & 6,3 & 2.6 \\
\hline Pygb & Rn. 1518 & 2.5 & NC & 1.9 & 0.5 \\
\hline Ass & Rn. 5078 & 2.8 & 0.8 & 2.5 & 1.6 \\
\hline Knkj16 & Rn. 1989 & 3.7 & NC & 3.9 & 3.3 \\
\hline Rdh10 & Rn. 19600 & 4.1 & NC & 0.9 & 0.8 \\
\hline Knk1 & Rn. 15693 & 2.2 & NC & 6.4 & 1.9 \\
\hline Vdup 1B & Rn. 2758 & 4.1 & 0.75 & 5.55 & 1.8 \\
\hline GCGB & Rn. 54383 & 5.8 & 2.2 & 6 & 5.6 \\
\hline$A C Y 1^{C}$ & Rn. 3679 & 3 & NC & 2.2 & 2.1 \\
\hline
\end{tabular}

\section{Adhesion/structure}

\begin{tabular}{|c|c|c|c|c|c|}
\hline Spna2 & Rn. 5812 & 2.1 & NC & 1.7 & 0.8 \\
\hline Ibsp & Rn. 9721 & 3.6 & NC & 1.6 & 3.7 \\
\hline$S d c 2$ & Rn. 11127 & 2.2 & NC & 2.4 & 1.3 \\
\hline Acta1 & Rn. 39438 & 3.8 & NC & 1.9 & 2.2 \\
\hline WASL & Rn. 104056 & 2.7 & NC & 1 & 2 \\
\hline \multicolumn{6}{|l|}{ Signaling } \\
\hline Gira1B & Rn. 10109 & 3.4 & NC & 1.4 & 2.4 \\
\hline$P d e 4 b$ & Rn. 2485 & 3 & NC & 3.25 & 1.6 \\
\hline Pde4d & Rn. 1004 & 2.4 & NC & 2.85 & 2.4 \\
\hline$P g f^{\mathrm{B}}$ & Rn. 6960 & 2.85 & NC & 4.25 & 2.95 \\
\hline Adra1bB & Rn. 10032 & 3.1 & 0.7 & 3.6 & 3.4 \\
\hline Pla2g $4 a^{B}$ & Rn. 10162 & 2.5 & NC & 1.4 & 1.9 \\
\hline Itpr2 & Rn. 89152 & 2.3 & I & 4 & 1 \\
\hline Lrp2 & Rn. 26430 & 3.1 & NC & 3.4 & 0.6 \\
\hline Ppp1r1b & Rn. 36206 & 3 & I & 2.9 & 2.9 \\
\hline Pak3B & Rn. 10128 & 4 & NC & 1.2 & 2.9 \\
\hline$R d c 1^{\mathrm{B}}$ & Rn. 12959 & 4.4 & 0.3 & 6.4 & 2.8 \\
\hline$I R S-2^{C}$ & Rn. 92308 & 3 & 0.5 & 3.5 & 1.3 \\
\hline Mig6 ${ }^{\mathrm{B}}$ & Rn. 100336 & 3.5 & 1.2 & 1.7 & 4.1 \\
\hline PEL/1B & Rn. 22814 & 2 & I & 1.5 & 2.6 \\
\hline PI4P5K-IB & Rn. 22148 & 2 & NC & 1.9 & 1.9 \\
\hline
\end{tabular}

SLR

Gene UniGene RET/PTC3 Y1062F HRAS BRAF

Inflammation/immunity

$\begin{array}{llcccc}\text { F10 } & \text { Rn. } 21393 & 3 & \text { NC } & 3,8 & 3.1\end{array}$

Proteolysis

$\begin{array}{llllll}K n g & \text { Rn. } 54394 & 3.3 & 3.85 & 5,55 & 4.6\end{array}$

Other

$\begin{array}{llllll}\text { Dig-1 } & \text { Rn. } 10656 & 2.3 & 0.9 & 1.5 & 2\end{array}$

$\begin{array}{llllll}\text { LOC } 207125^{C} & \text { Rn. } 10718 & 2.4 & \text { NC } & 2.5 & 1.5\end{array}$

Tcp1

$\begin{array}{lllll}\text { Rn. } 7102 & 3.2 & 2 & 2.6 & 2.2\end{array}$

EST

AA875654

AA892287

AA892779

AA893192

AA899685

AA925302

AA945679

AA946224

AA955287

AA956626

AA956720

AA957707

AA957835

AA963282

AA964069

AA964863

AA965122

AA998543

AA998660

Al008390

Al009321

Al009822

Al010157

Al013875

Al029070

Al029492

Al029741

Al030145

Al030350

Al030351

Al030569

Al043701

Al043942

Al045936

Al058357

Al058863

Al059078

Al070112

Al070185

Al639238

Al639473 $\begin{array}{lllll} & 2.4 & 0.5 & 1.1 & 1.1\end{array}$

$\begin{array}{lllll}\text { Rn. } 7319 & 2.5 & 1.1 & 2.3 & 0.7\end{array}$

$\begin{array}{lllll}\text { Rn. } 3568 & 6.2 & 0.2 & 3.9 & 4.3\end{array}$

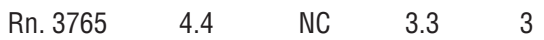

$\begin{array}{lllll}\text { Rn. } 8149 & 2.4 & 0.6 & 3.7 & 2.6\end{array}$

$\begin{array}{lllll}\text { Rn. } 22639 & 2.7 & 0.5 & 5.9 & 0.7\end{array}$

$\begin{array}{lllll}\text { Rn. } 8470 & 2 & \text { NC } & 2.2 & 0.9\end{array}$

$\begin{array}{lllll}\text { Rn. } 3271 & 2.2 & \text { NC } & 2.4 & 1.3\end{array}$

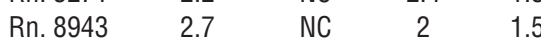

$\begin{array}{lllll}\text { Rn. } 9069 & 5.4 & \text { I } & 6.3 & 1.3\end{array}$

$\begin{array}{lllll}\text { Rn. } 9366 & 3.2 & 0.7 & 1.7 & 2.1\end{array}$

$\begin{array}{lllll}\text { Rn. } 104138 & 2.5 & \text { I } & 3.6 & 2.4\end{array}$

$\begin{array}{lllll}\text { Rn. } 11431 & 2.6 & 1.2 & 3.3 & 1.5\end{array}$

$\begin{array}{lllll}\text { Rn. } 26652 & 2 & \text { NC } & 3.4 & 3.9\end{array}$

$\begin{array}{lllll}\text { Rn. } 23239 & 5.6 & \text { I } & 7.4 & 6.5\end{array}$

$\begin{array}{lllll}\text { Rn. } 12011 & 2.5 & 0.8 & 4.8 & 1.8\end{array}$

$\begin{array}{lllll}\text { Rn. } 105756 & 3 & 0.6 & 4.4 & 1\end{array}$

$\begin{array}{lllll}\text { Rn. } 13814 & 2.2 & \text { I } & 4.3 & 3\end{array}$

$\begin{array}{lllll}\text { Rn. } 22641 & 2.2 & \text { NC } & 1 & 2.2\end{array}$

$\begin{array}{lllll}\text { Rn. } 25030 & 2.6 & 0.3 & 7 & 2.4\end{array}$

$\begin{array}{lllll}\text { Rn. } 17350 & 4.1 & \text { I } & 6 & 1.8\end{array}$

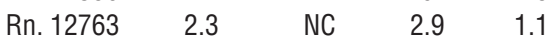

$\begin{array}{lllll}\text { Rn. } 18139 & 3.5 & \text { NC } & 4.1 & 0.9\end{array}$

$\begin{array}{lllll}\text { Rn. } 18238 & 3.7 & 0.6 & 3.8 & 3.6\end{array}$

$\begin{array}{lllll}\text { Rn. } 18312 & 4.4 & 2.3 & 3.2 & 2.2\end{array}$

$\begin{array}{lllll}\text { Rn. } 21563 & 2.3 & 2.3 & 1.9 & 3.2\end{array}$

$\begin{array}{lllll}\text { Rn. } 21579 & 5.3 & 3.4 & 5.2 & 3.4\end{array}$

$\begin{array}{lllll}\text { Rn. } 25503 & 5.1 & 2 & 3.5 & 4.1\end{array}$

$\begin{array}{llll}2.1 & 2.4 & 4.5 & 4.8\end{array}$

$\begin{array}{lllll}\text { Rn. } 17424 & 2.8 & \text { I } & 4.3 & 2.3\end{array}$

$\begin{array}{lllll}\text { Rn. } 20936 & 3.7 & \text { NC } & 2.2 & 4.7\end{array}$

$\begin{array}{lllll}\text { Rn. } 18850 & 2.5 & \text { NC } & 9.5 & 2.1\end{array}$

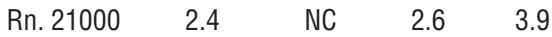

$\begin{array}{lllll}\text { Rn.19060 } & 3.6 & \text { I } & 4.8 & 4.3\end{array}$

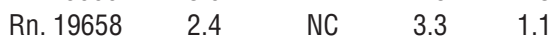

$\begin{array}{lllll}\text { Rn. } 19684 & 3.2 & \text { NC } & 1.8 & 1.5\end{array}$

$\begin{array}{lllll}\text { Rn. } 8434 & 3.5 & \text { NC } & 0.6 & 0.8\end{array}$ $\begin{array}{lllll}\text { Rn. } 3658 & 2.4 & \text { NC } & 3.7 & 1.2\end{array}$

AThe genes downregulated in RET/PTC3 cells 4 -fold or more and also downregulated in HRAS and BRAF cells are listed. BTargets whose downregulation was confirmed by RT-PCR. CTargets whose downregulation was not confirmed. Targets not further studied by PCR are unmarked. I, increased. 
Table 3

Gene expression levels in transformed PC cells by Q-RT-PCR

\begin{tabular}{|c|c|c|c|c|c|c|c|c|c|c|c|c|}
\hline \multicolumn{13}{|c|}{ Cell type } \\
\hline \multirow[t]{2}{*}{ Genes $^{A}$} & & \multicolumn{3}{|c|}{ PTC3 } & \multicolumn{3}{|c|}{ BRAF } & \multicolumn{5}{|c|}{ HRAS } \\
\hline & Cl1 & $\mathrm{Cl} 2$ & Pool no. 3 & $P^{c}$ & $\mathrm{Cl} 1$ & $\mathrm{Cl} 2$ & Pool no. 3 & $P C$ & Cl1 & $\mathrm{Cl} 2$ & Pool no. 3 & $P \mathrm{C}$ \\
\hline \multicolumn{13}{|c|}{ Upregulated } \\
\hline Adm & 10.6 & 10.6 & 13.3 & $<0.05$ & 9 & 7.8 & 9.1 & $<0.05$ & 1.6 & 2.2 & 2.8 & $<0.05$ \\
\hline Dups6 & 78.6 & 51 & 39.9 & $<0.05$ & 25 & 32.5 & 89.1 & $<0.05$ & $>100$ & $>100$ & $>100$ & $<0.05$ \\
\hline Itga1 & 9.2 & 12.3 & 5.8 & $<0.05$ & 16.4 & 13.7 & 24.3 & $<0.05$ & 1.7 & 1.5 & 1.7 & $<0.05$ \\
\hline Sgk & 8 & 5 & 7.5 & $<0.05$ & 9.4 & 9.2 & 9.2 & $<0.05$ & 6.2 & 7.1 & 9.3 & $<0.05$ \\
\hline PI4K2B & 6.2 & 6.5 & 2.6 & $<0.05$ & 11.2 & 12.1 & 23.7 & $<0.05$ & 1.75 & 1.92 & 2.92 & $<0.05$ \\
\hline Fhl2 & 10.3 & 9.6 & 6.2 & $<0.05$ & 9.5 & 10.5 & 10.6 & $<0.05$ & 7.6 & 7.9 & 13.3 & $<0.05$ \\
\hline CITED2 & 2.5 & 9.2 & 1.4 & $<0.05$ & 26.7 & 13.3 & 10.8 & $<0.05$ & 2.6 & 2.9 & 1.7 & $<0.05$ \\
\hline Spp1 & 20 & 15.5 & 37 & $<0.05$ & 3.5 & 11.9 & 5 & $<0.05$ & 30 & $>100$ & 45 & $<0.05$ \\
\hline CCL2 & 97 & 57 & 50 & $<0.05$ & 37.8 & $>100$ & $>100$ & $<0.05$ & 27.3 & 12.1 & 6.9 & $<0.05$ \\
\hline CXCL1 & 42 & 35.9 & 14.5 & $<0.05$ & $>100$ & 67 & 80.6 & $<0.05$ & 19.7 & 17.1 & 14.6 & $<0.05$ \\
\hline Mmp13 & $>100$ & $>100$ & 32.7 & $<0.05$ & 8.5 & 6.2 & 10 & $<0.05$ & 27.9 & 48.5 & 35.9 & $<0.05$ \\
\hline Mmp10 & $>100$ & $>100$ & $>100$ & $<0.05$ & $>100$ & $>100$ & $>100$ & $<0.05$ & 48.5 & 59.7 & 44.2 & $<0.05$ \\
\hline Mmp12 & $>100$ & $>100$ & 48.5 & $<0.05$ & 15.1 & 8.6 & 10 & $<0.05$ & 1.8 & 1.9 & 2.1 & $<0.05$ \\
\hline Mmp3 & $>100$ & $>100$ & 46.3 & $<0.05$ & 1.6 & 1 & 10 & $>0.05$ & 12.4 & 18.8 & 9.8 & $<0.05$ \\
\hline USP18-like & 31.4 & 28 & 18.2 & $<0.05$ & 7.6 & 18 & 12.7 & $<0.05$ & 3.6 & 4.2 & 4.8 & $<0.05$ \\
\hline Th & 20.6 & 45.3 & 21.6 & $<0.05$ & 11.1 & 18.4 & 8.7 & $<0.05$ & 19 & 21.6 & 18.6 & $<0.05$ \\
\hline Ca2 & 17.6 & 9.9 & 23.3 & $<0.05$ & 4 & 1.9 & 3 & $>0.05$ & 1.3 & 1.5 & 1.9 & $<0.05$ \\
\hline Lgals3 & 19.2 & 19.7 & 9.8 & $<0.05$ & 12.1 & 3.7 & 9.8 & $<0.05$ & 5.3 & 4.2 & 3 & $<0.05$ \\
\hline Lgals1 & 4.4 & 4.9 & 6.5 & $<0.05$ & 2.7 & 1.5 & 1.9 & $<0.05$ & 1.6 & 4 & 1.5 & $<0.05$ \\
\hline$T m s b 4 x$ & 7.5 & 7.6 & 13.4 & $<0.05$ & 1.7 & 2 & 2.6 & $<0.05$ & 4.9 & 10.8 & 6.4 & $<0.05$ \\
\hline Dysf2-like & 13.3 & 8.6 & 19.7 & $<0.05$ & 4.2 & 3 & 2 & $<0.05$ & 56.8 & 69.7 & 54.4 & $<0.05$ \\
\hline S100A4 & 12.5 & 9 & 33.5 & $<0.05$ & 2.5 & 1.2 & 3.8 & $>0.05$ & 3.1 & 6.2 & 10.4 & $<0.05$ \\
\hline S100A6 & 13.5 & 3.5 & 18.9 & $<0.05$ & 12 & 3.8 & 3 & $<0.05$ & 6,2 & 8 & 10.3 & $<0.05$ \\
\hline \multicolumn{13}{|c|}{ Downregulated } \\
\hline Gas6 & 0.04 & 0.02 & 0.01 & $<0.05$ & 0.005 & 0.08 & 0.02 & $<0.05$ & 0.01 & 0.01 & 0.02 & $<0.05$ \\
\hline Crem & 0.1 & 0.14 & 0.06 & $<0.05$ & 0.2 & 0.2 & 0.2 & $<0.05$ & 0.04 & 0.08 & 0.05 & $<0.05$ \\
\hline Hhex & 0.1 & 0.07 & 0.12 & $<0.05$ & 0.1 & 0.04 & 0.07 & $<0.05$ & 0.02 & 0.03 & 0.1 & $<0.05$ \\
\hline IRF8 & 0.003 & 0.004 & 0.003 & $<0.05$ & 0.008 & 0.01 & 0.008 & $<0.05$ & 0.004 & 0.004 & 0.009 & $<0.05$ \\
\hline Vdup1 & 0.35 & 0.07 & 0.1 & $<0.05$ & 0.06 & 0.03 & 0.02 & $<0.05$ & 0.02 & 0.02 & 0.01 & $<0.05$ \\
\hline GCG & $<0.001$ & $<0.001$ & 0.001 & $<0.05$ & $<0.001$ & $<0.001$ & $<0.001$ & $<0.05$ & $<0.001$ & $<0.001$ & $<0.001$ & $<0.05$ \\
\hline Gira1 & 0.2 & 0.4 & 0.3 & $<0.05$ & 0.5 & 0.5 & 0.5 & $<0.05$ & 0,3 & 0.4 & 0.2 & $<0.05$ \\
\hline Pgf & 0.06 & 0.1 & 0.04 & $<0.05$ & 0.1 & 0.02 & 0.08 & $<0.05$ & 0.006 & 0.005 & 0.006 & $<0.05$ \\
\hline Adra1b & 0.028 & 0.013 & 0.01 & $<0.05$ & 0.03 & 0.02 & 0.01 & $<0.05$ & 0.05 & 0.05 & 0.01 & $<0.05$ \\
\hline Pla2g4A & 0.05 & 0.11 & 0.02 & $<0.05$ & 0.2 & 0.1 & 0.1 & $<0.05$ & 0.007 & 0.01 & 0.007 & $<0.05$ \\
\hline Pak3 & 0.17 & 0.7 & 0.07 & $>0.05$ & 0.4 & 0.5 & 0.6 & $<0.05$ & 0.008 & 0.01 & 0.008 & $<0.05$ \\
\hline$R d c 1$ & 0.02 & 0.01 & 0.02 & $<0.05$ & 0.16 & 0.07 & 0.01 & $<0.05$ & 0.023 & 0.04 & 0.03 & $<0.05$ \\
\hline Mig-6 & 0.2 & 0.3 & 0.3 & $<0.05$ & 0.7 & 0.7 & 1.4 & $>0.05$ & 0.1 & 0.2 & 0.2 & $<0.05$ \\
\hline PELI1 & 0.18 & 0.44 & 0.13 & $<0.05$ & 0.16 & 0.1 & 0.3 & $<0.05$ & $<0.001$ & $<0.001$ & 0.3 & $<0.05$ \\
\hline
\end{tabular}

AGenes are classified as up- or downregulated based on their behavior in RET/PTC3-transformed with respect to parental PC cells. ${ }^{\mathrm{B} G e n e}$ expression levels are expressed as fold change with respect to parental PC cells. PCRs were performed in triplicate; SD was always $<15 \%$. ${ }^{\mathrm{C}} \mathrm{Significance}$ was determined by the Mann-Whitney $U$ test. $P<0.05$ was considered statistically significant. Samples in which $P$ values were not statistically significant are indicated in bold.

Figure 7B. Treatment with recombinant CXCL1 and CXCL10 stimulated (about 2- to 3-fold) DNA synthesis of TPC1 cells. In contrast, treatment with selective receptor antagonists or blocking antibodies, but not with nonspecific IgG, impaired basal DNA synthesis (about 2-fold). Finally, we asked whether chemokines stimulated cell invasiveness through Matrigel. Representative micrographs are shown in Figure 7C (left) together with the average results of 3 independent assays (right). TPC1 cells had basal levels of invasiveness; exogenous CXCL1 or CXCL10 further induced a strong migratory response. Basal TPC1 migration through Matrigel was inhibited by treatment with PTX, with CXCR2- or CXCR3-blocking antibodies, and with CXCL1- or CXCL10-blocking antibodies but not with nonspecific IgG. Cell motility was also blocked by selective CXCR2 (SB225002) and CXCR3 (TAK-779) antagonists (33, 34). Finally, treatment of TPC1 cells with BRAF siRNA and U0126 inhibited basal migration in Matrigel. This effect was not observed when a scrambled control was used (Figure 7D).

\section{Discussion}

A RET/PTC-RAS-BRAF pathway drives thyroid cancer initiation. Here we show that the oncogenic proteins involved in the initiation of PTC work along the same signaling cascade. This pathway starts at the 


\section{Table 4}

BRAF/MEK dependence of gene expression levels in PC RET/ PTC3 cells

\begin{tabular}{|c|c|c|c|}
\hline Gene $^{A}$ & U0126 & Treatment ${ }^{B}$ siRNA (SCR) & siRNA (BRAF) \\
\hline \multicolumn{4}{|c|}{ Upregulated } \\
\hline Dusp6 & 0.065 & NC & 0.43 \\
\hline Sgk & 0.5 & NC & 0.8 \\
\hline Spp1 & 0.14 & NC & 0.3 \\
\hline CCL2 & 0.3 & NC & 0.4 \\
\hline CXCL1 & 0.16 & NC & 0.4 \\
\hline Mmp12 & 0.5 & NC & 0.5 \\
\hline Mmp3 & 0.19 & NC & 0.28 \\
\hline Mmp13 & 0.03 & NC & 0.3 \\
\hline $\mathrm{Ca} 2$ & 0.25 & NC & NC \\
\hline Dysf2-like & 0.2 & NC & 0.7 \\
\hline S100A6 & 0.4 & NC & 0.25 \\
\hline \multicolumn{4}{|c|}{ Downregulated } \\
\hline Gas6 & 20 & NC & 3 \\
\hline Crem & 200 & NC & 5 \\
\hline Vdup1 & 2 & NC & 2 \\
\hline GCG & 4 & NC & 15 \\
\hline Glra1 & 2 & NC & 7 \\
\hline Pgf & 2.3 & NC & 2.5 \\
\hline Adra1b & 2 & NC & 4.6 \\
\hline Pla2g4a & 4 & NC & 2.5 \\
\hline Pak3 & 2.4 & NC & 7.1 \\
\hline$R d c 1$ & 2.5 & NC & 2 \\
\hline PEL/1 & 2 & NC & 2 \\
\hline
\end{tabular}

AGenes are classified as up- or downregulated based on their behavior in RET/PTC3-transformed with respect to parental PC cells.

BGene expression levels are expressed as fold change with respect to RET/PTC3 cells. NC, expression level not changed with respect to untreated RET/PTC3 cells.

level of RET tyrosine 1062 and sequentially triggers RAS, BRAF, and ERK stimulation. These conclusions are supported by a body of experimental evidence. First, the transient block of RAS or BRAF activity in HEK293 cells, either by dominant negative mutants or by RNA interference, inhibited RET/PTC-mediated ERK activation. Second, in a thyroid cell setting, RET/PTC3-induced ERK activity depended on BRAF. Finally, the biological effects mediated by RET/ PTC3, i.e., cell proliferation and Matrigel invasion, depended on the integrity of the RET/PTC3-RAS-BRAF pathway.

According to such a model, in PC thyroid cells, the 3 activated oncoproteins stimulated largely overlapping gene expression signatures. Most of the common targets were under the control of RET/PTC(Y1062), and the use of BRAF siRNA and chemical blockade of MEK demonstrated that 22 of the 37 genes tested were under the control of the RET/PTC3-RAS-BRAF-ERK cascade. Consistently, some genes had been previously shown to be regulated via the MAPK cascade. One example is DUSP6, a dual-specificity protein phosphatase, which binds to and inactivates ERK1/2 (35). It is likely that the gene expression signature shared by cells transformed by RET/PTC, RAS, or BRAF characterizes a vast number of PTCs. Accordingly, our analysis of a small sample set of primary tumors showed that this gene expression signature may be exploited as a clinical diagnostic test. A larger number of samples will be required to refine the test and to determine whether it is sufficiently robust for clinical implementation.

One corollary of these observations is that therapeutic approaches can be tailored to target the proteins that act downstream from this cascade. Although selective RET kinase inhibitors (36) are effective only in tumors featuring RET rearrangements, and not in those carrying activating mutations in genes functioning downstream from the cascade, chemical blockade of BRAF (37) might be beneficial in carcinomas characterized by oncogenic activation of 1 of the 3 proteins. Moreover, our findings imply that other proteins coupled, at different levels, to the RET/PTC-RAS-BRAF cascade could be involved in PTC samples negative for mutations in the 3 oncoproteins. For instance, it is likely that oncogenic versions of the TRKA receptor, which occur in a small fraction of PTCs (8), substitute RET/PTC upstream from the cascade. It is also conceivable that proteins that modulate the transmission of signals among RET, RAS, BRAF, and ERK can modify the phenotype of thyroid tumors carrying mutations at different levels of the cascade.

Differences in RET/PTC-, RAS-, and BRAF-driven transcriptional profiles. The analysis of transcriptional profiles indicated that the 3 oncoproteins are not completely equivalent. Indeed, in addition to targets common to RET/PTC3, HRAS, and BRAF, there were relatively large sets of genes specifically modulated by only 1 or 2 of the 3 oncogenes. Overall, the similarity between transcriptional

\section{Figure 5}

Expression levels of selected genes (A) and chemokines (B) in human PTC samples versus 5 normal thyroid tissues as determined by Q-RT-PCR. The PTC samples were characterized for the presence of either a RET/PTC rearrangement or a $B R A F(\mathrm{~V} 600 \mathrm{E})$ mutation. For each target (indicated on the $x$ axis), the expression levels values of tumors ( $y$ axis) were calculated relative to the average expression level in normal tissues (TN). All the experiments were performed in triplicate; SDs were smaller than $25 \%$ in all cases (data not shown). $P$ values were calculated by the Mann-Whitney $U$ test.
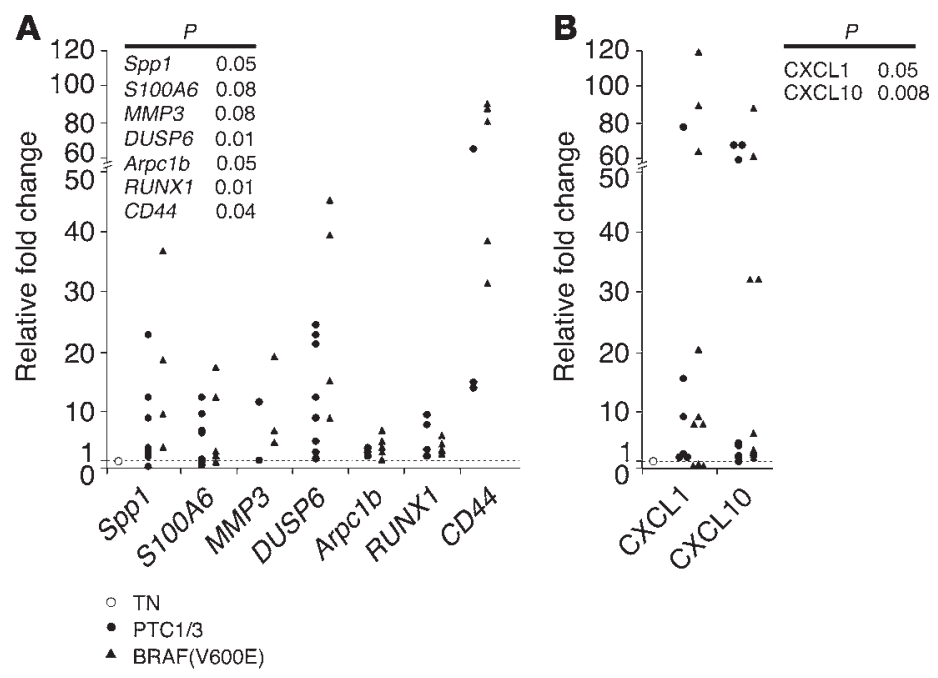
A

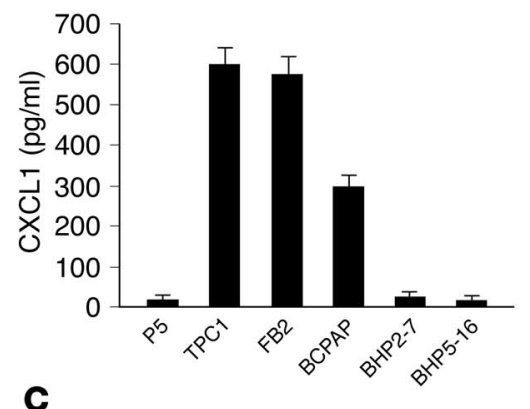

C
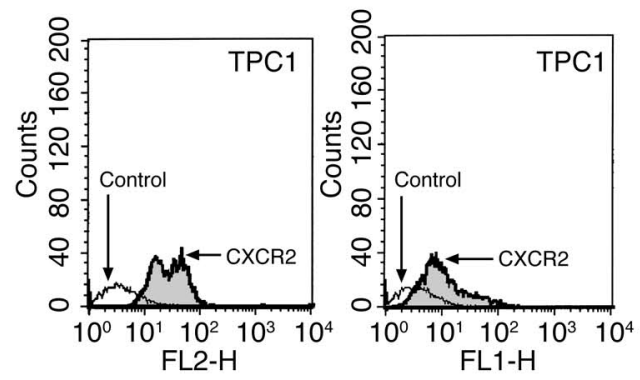

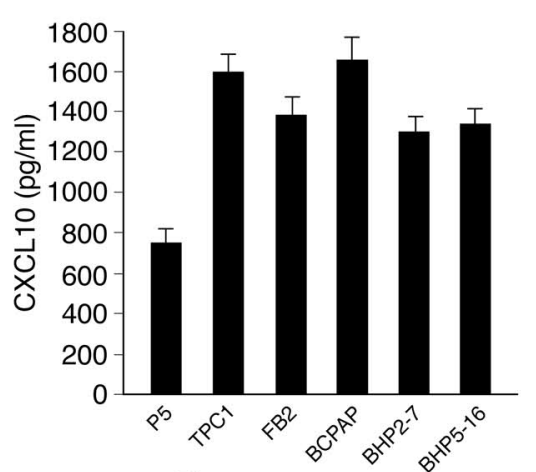

D

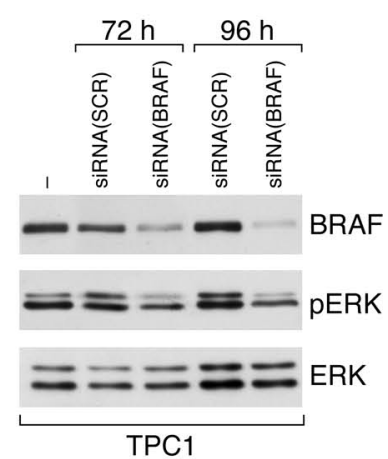

B

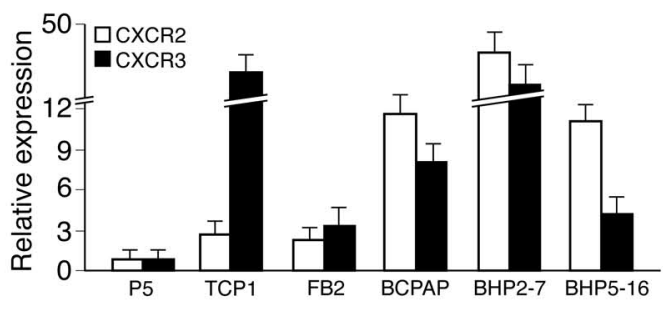

$\mathbf{E}$

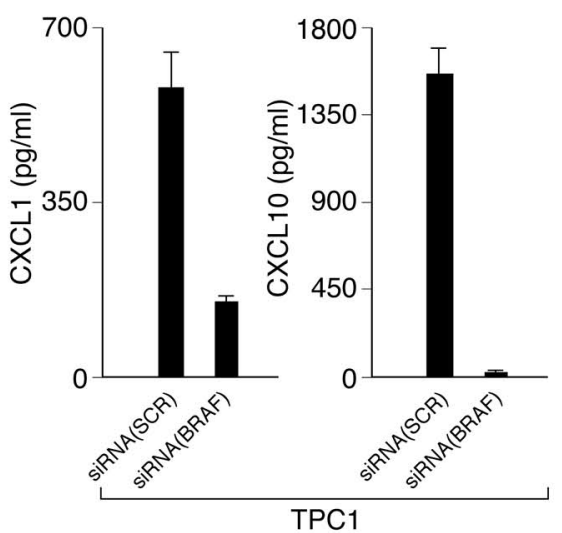

Figure 6

Chemokines and chemokine receptors are expressed in human PTC-derived cell lines. (A) CXCL1 and CXCL10 secretion in human PTC cells was evaluated by ELISA. Experiments were performed in triplicate, and the average value of the results \pm SD was plotted. Normal thyroid cells (P5) were used as a negative control. (B) Expression levels of CXCR2 and CXCR3 in PTC cell lines were evaluated by Q-RT-PCR. Expression values were calculated relative to the expression level in normal P5 cells. Experiments were performed in triplicate, and the average value of the results \pm SD was plotted. (C) Flow cytometric analysis of surface expression of CXCR2 and CXCR3 in TPC1 cells. (D) TPC1 cells were transfected by BRAF or scrambled siRNA and harvested 72 or 96 hours later. Protein lysates were subjected to immunoblotting with anti-BRAF and anti-phospho-p44/p42 ERK antibodies. (E) BRAF siRNA interference in TPC1 cells affected chemokine production as determined by ELISA.

profiles of HRAS(V12) and BRAF(V600E) thyroid cells was greater than that between RET/PTC3 and HRAS or RET/PTC3 and BRAF cells. For instance, HRAS and BRAF cells (but not RET/PTC cells) were characterized by overexpression of genes such as $I L-6, C X C R 1$, PDGF- $\alpha$, SPARC, MCM6, RAF1, and Akt and by downregulation of PLC- $\beta 1$. This was not unexpected; although the 3 oncoproteins work together along a single cascade, they are biochemically different and therefore able to trigger specific signals in addition to the common ones. Molecular genetics evidence nicely supports this concept. For instance, $B R A F$ mutations are frequently associated with aggressive thyroid carcinomas, such as poorly differentiated and anaplastic carcinomas, that rarely, if ever, harbor RET/PTC rearrangements (28). On the other hand, RAS point mutations are rare in classic PTCs and, instead, characterize PTCs of the follicular variant that are rarely affected by mutations in BRAF or RET (9). Detailed analysis of the gene expression signatures in a large set of samples may help to identify molecular profiles that characterize each oncoprotein.

Function of the genes modulated by RET/PTC3, HRAS(V12) and $B R A F(V 600 E)$. Many of the commonly modulated genes were involved in hallmarks of neoplastic transformation, e.g., altered cell morphology, uncontrolled growth, loss of differentiation, and apoptosis. Induced genes included MMPs (MMP3, -10, -12, -13) (38). Another category of genes that was greatly overexpressed in transformed PC cells were those encoding adhesion/structure-associated proteins, such as collagen 1 (Col1 $\alpha 1)$, thymosin $\beta 4$, and galectin-3, previously reported to be overexpressed in thyroid carcinomas (39-42). The dual-specificity phosphatase (DUSP6) was also previously identified as a gene upregulated in human PTC samples (41). Finally, upregulated genes included those coding for S100A4 (p9KA) and S100A6 (calcyclin); their elevated levels have been associated with cancer and metastasis (43). Consistent with the loss of the differentiated phenotype of transformed cells, genes coding for differentiation markers were downregulated. Interestingly, the gene Hhex, which encodes for a proline-rich homeodomain transcription factor and is regulated by thyroid-specific transcription factors, such as TTF-1 and PAX8 (44), was also downregulated. Another downregulated gene was mitogen-inducible gene-6 (Mig6). This protein is a negativefeedback regulator of the epidermal growth factor receptor and a potential tumor suppressor (45).

Chemokine autocrine loops in transformed thyroid cells. PTC is associated with a striking chronic inflammatory reaction in about $30 \%$ of cases $(1,32)$. Our data provide a molecular explanation for this phenomenon by showing that the RET/PTC-RAS-BRAF signaling cascade that drives PTC initiation stimulates the overexpression of several chemokines. In turn, chemokines secreted by tumor cells 

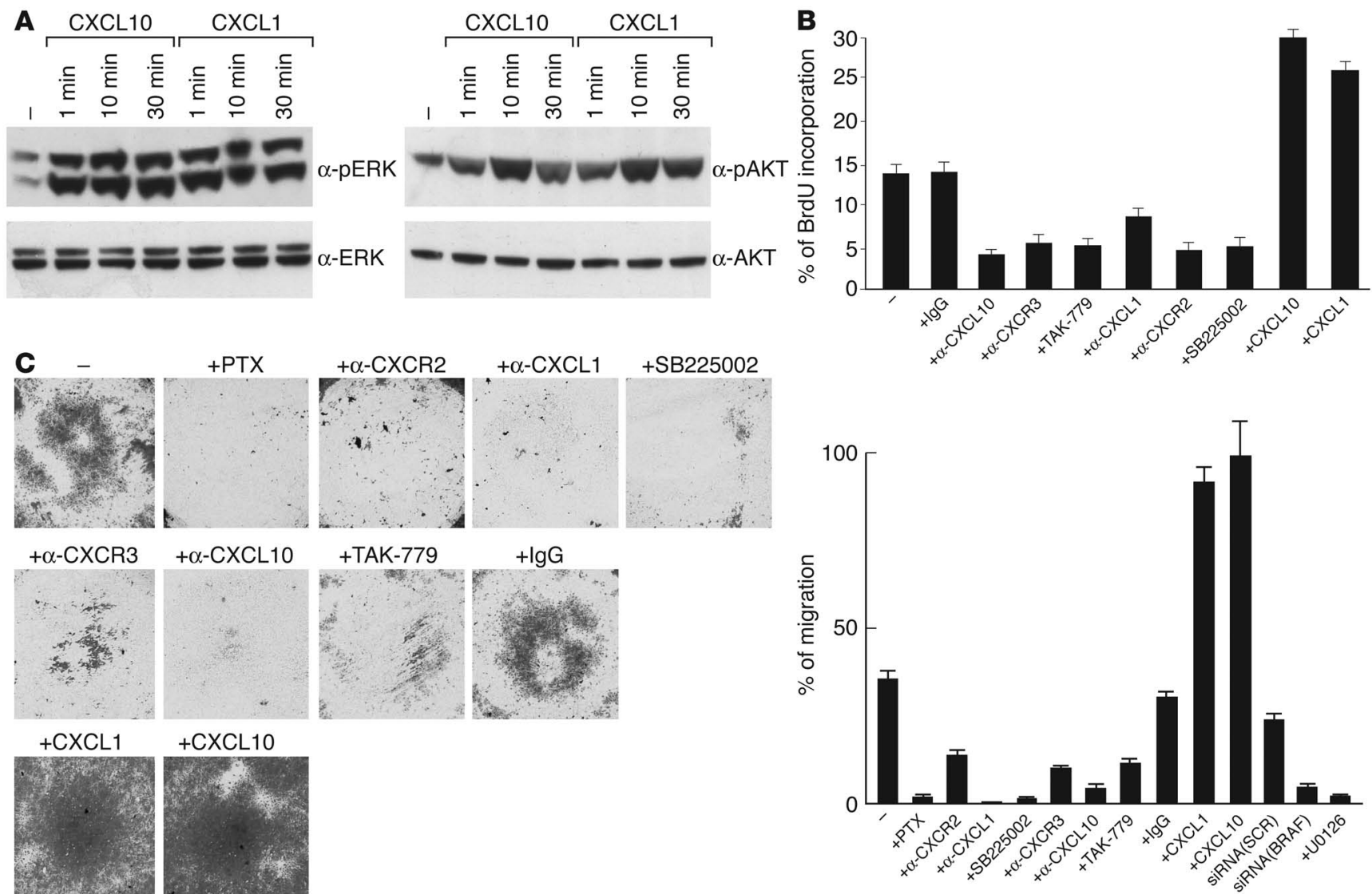

Figure 7

Functional activities of CXCL1 and CXCL10 in human PTC cell lines. (A) Stimulation with CXCL1 and CXCL10 (100 ng/ml) induced time-dependent ERK and AKT activation in TPC1 cells. Cell lysates were harvested at the indicated time points; Western blots were probed with the indicated antibodies. (B) BrdU incorporation was measured to evaluate S-phase entry upon treatment with CXCL1 or CXCL10 or the indicated inhibitors. The average of the results of 3 independent experiments \pm SD is indicated. (C) TPC1 cells were allowed to migrate for 24 hours toward serumfree medium or, where indicated, a gradient of CXCL1 or CXCL10. Where indicated, cells were preincubated with blocking antibodies, control antibodies, chemical inhibitors, or PTX. Cells were treated with either BRAF siRNA or U0126. Representative micrographs (left) and absorbance at $570 \mathrm{~nm}$ (average \pm SD of 3 experiments; right) are shown.

can recruit leukocytes (macrophages, dendritic cells, $\mathrm{T}$ cells, and natural killer cells) to tumor sites $(30,31)$. An interesting aspect of the relationship between inflammation and cancer is that several tumors use molecules of the innate immune system not only to recruit leukocytes, but also for growth, survival, and metastasis. It can be envisaged that a mixture of chemokines is produced in the tumor microenvironment and act in an autocrine/paracrine fashion between neighboring homotypic cells $(46,47)$. Expression of CXCR2 and CXCR3, the receptors for CXCL1 and CXCL10, respectively, was detected in transformed thyroid cells. Therefore, 2 autocrine/paracrine loops may mediate biological activities in PTCs that are relevant for the establishment of the neoplastic phenotype, e.g., autonomous proliferation and motility.

In conclusion, we propose that PTCs are initiated by a set of transforming events that target proteins that act along a linear signaling cascade. Activation of this signaling cascade results in upregulation of chemokines and their receptors that are relevant for sustained proliferation and cell motility of tumor cells. We suggest that these genes may act cooperatively to commit transformed thyroid cells to a malignant invasive phenotype.

\section{Methods}

Plasmids. All the molecular constructs used in this study were cloned in pCDNA3(Myc-His) (Invitrogen Corp.). The RET/PTC constructs encode the short spliced form of RET (RET9) and are described elsewhere (22). For simplicity, we numbered the residues of RET/PTC proteins according to the corresponding residues in unrearranged RET. RET/PTC1 and RET/PTC3 constructs encode the H4-RET and RFG-RET chimeric oncogenes, respectively. RET/PTC $3\left(\mathrm{~K}^{-}\right)$is a kinase-dead mutant, carrying the substitution of the catalytic lysine (residue 758 in full-length RET) with a methionine. RET/PTC3(Y1062F) and RET/PTC3(Y1015F) carry substitutions of the indicated tyrosines with phenylalanine residues. BRAF and the kinase-dead $\mathrm{BRAF}\left(\mathrm{K}^{-}\right)$were kindly donated by C.J. Marshall (Institute of Cancer Research, London, United Kingdom) (12). BRAF(V600E) was obtained by site-directed mutagenesis using the QuickChange mutagenesis kit (Stratagene). The mutation was confirmed by DNA sequencing. HRAS(V12) and HRAS(N17) plasmids are described elsewhere (23).

Cell cultures and transfections. $\mathrm{PC} \mathrm{Cl} 3$ (PC) is a differentiated thyroid follicular cell line derived from 18-month-old Fischer rats. PC cells were cultured in Coon's modified Ham F12 medium supplemented with 5\% calf serum and a mixture of $6 \mathrm{H}$, including thyrotropin $(10 \mathrm{mU} / \mathrm{ml})$, hydro- 
cortisone $(10 \mathrm{nM})$, insulin $(10 \mu \mathrm{g} / \mathrm{ml})$, apo-transferrin $(5 \mu \mathrm{g} / \mathrm{ml})$, somatostatin $(10 \mathrm{ng} / \mathrm{ml})$, and glycyl-histidyl-lysine $(10 \mathrm{ng} / \mathrm{ml})$ (Sigma-Aldrich) (24). For stable transfections, $5 \times 10^{5} \mathrm{PC}$ cells were plated 48 hours before transfection in $60-\mathrm{mm}$ tissue culture dishes. The medium was changed to DMEM (Invitrogen Corp.) containing 5\% calf serum and $6 \mathrm{H}$. Three hours later, calcium phosphate DNA precipitates were incubated with the cells for 1 hour. DNA precipitates were removed, and cells were washed with serumfree DMEM and incubated with $15 \%$ glycerol in HEPES-buffered saline for 2 minutes. Finally, cells were washed with DMEM and incubated in Coon's modified F12 medium supplemented with $5 \%$ calf serum and $6 \mathrm{H}$. Two days later, G418 (neomycin) was added at a concentration of $400 \mu \mathrm{g} / \mathrm{ml}$. Mass populations (pool no. 3) of several PC cell clones were pooled and expanded; 2 independent cell clones ( $\mathrm{Cl} 1$ and $\mathrm{Cl} 2$ ) for each transfection were also isolated. For the colony formation assay, 2 dishes of PC were transfected with each plasmid. Two days later, G418 was added to 1 dish, whereas the other dish was kept in medium containing $5 \%$ calf serum without $6 \mathrm{H}$. After 15 days, cells colonies were fixed in $11 \%$ glutaraldehyde in PBS, rinsed in distilled water, stained with $0.1 \%$ crystal violet in $20 \%$ methanol for 15 minutes, and counted. The percentage of hormone-independent colonies with respect to the total number of G418-resistant colonies was calculated as the average of 3 independent determinations \pm SD. HEK293 cells were from American Type Culture Collection and were grown in DMEM supplemented with $10 \%$ fetal calf serum. Transient transfections were carried out with $5 \mu$ g of total DNA in the Lipofectamine reagent according to the manufacturer's instructions (Invitrogen Corp.). TPC1, FB2, BCPAP, BHP2-7, and BHP5-16 human PTC cell lines were grown in DMEM supplemented with $10 \%$ fetal calf serum. The P5 primary culture of normal human thyroid follicular cells was kindly donated by F. Curcio (University of Udine, Udine, Italy) and was grown as previously described (48).

RNA silencing. siRNAs targeting human BRAF are described elsewhere (49). Duplex oligonucleotides targeting rat BRAF were designed with a siRNA selection program (50) and were chemically synthesized by PROLIGO. Sense strands for siRNA targeting were: rat BRAF, 5'AAAGCCACAGCUGGCUAUUGUUA-3'; human BRAF, 5' -AGAAUUGGAUCUGGAUCAUdTdT-3'; and scrambled, 5'-rArCrCrgUrCrgrAUUUrCrArCrCrCrgrgTT-3'. For siRNA transfection, PC RET/PTC3 and TPC1 cells were grown under standard conditions. The day before transfection, cells were plated in 6-well dishes at 50-60\% confluency. Transfection was performed using 5-15 $\mu \mathrm{g}$ of duplex RNA and $6 \mu \mathrm{l}$ of Oligofectamine reagent (Invitrogen Corp.), as previously described (49). Cells were harvested at different time points after transfection and analyzed.

Tissue samples. Archival frozen thyroid tissue samples from 18 patients affected by PTCs were retrieved from the files of the Pathology Department of the University of Pisa upon informed consent. Special care was taken to select cases whose corresponding histological samples were available for matched analysis. Sections ( $4 \mu \mathrm{m}$ thick) of paraffin-embedded samples were stained with $\mathrm{H} \& \mathrm{E}$ for histological examination to ensure that the samples fulfilled the diagnostic criteria required for the identification of PTCs (enlarged nuclei with fine, dusty chromatin, nuclear grooves, single or multiple micro-/macronucleoli, and intranuclear inclusions). Normal thyroid tissue samples were also retrieved from the files of the Pathology Department of the University of Pisa upon informed consent. All experiments were approved by the "Comitato etico per la sperimentazione clinica del farmaco" of the Azienda Ospedaliera - Universitaria Pisana (Pisa, Italy).

RNA extraction and RT-PCR. Total RNA was isolated using the RNeasy Kit (QIAGEN) and subjected to on-column DNase digestion with the RNasefree DNase set (QIAGEN) according to the manufacturer's instructions. Where indicated, cells were transfected with BRAF siRNA or treated with $\mathrm{U} 0126(20 \mu \mathrm{M})$ and harvested 72 hours after treatment. The quality of RNA was verified by electrophoresis through $1 \%$ agarose gel and visualized with ethidium bromide. We synthesized random-primed first-strand cDNA in a 50- $\mu \mathrm{l}$ reaction volume starting from $2 \mu \mathrm{g}$ RNA using the GeneAmp RNA PCR Core Kit (Applied Biosystems). Primers were designed using Primer3 software (http://frodo.wi.mit.edu/cgi-bin/primer3/primer3_www.cgi) and synthesized by MWG Biotech. Primer sequences are available in Supplemental Tables 2 and 3. To exclude DNA contamination, each PCR reaction was also performed on untranscribed RNA. We performed Q-RT-PCRs using the SYBR Green PCR Master Mix (Applied Biosystems) in the iCycler apparatus (Bio-Rad). Amplification reactions ( $25 \mu \mathrm{l}$ final reaction volume) contained $200 \mathrm{nM}$ of each primer, $3 \mathrm{mM} \mathrm{MgCl}_{2}, 300 \mu \mathrm{M}$ deoxyribonucleoside triphosphates (dNTPs), $1 \times$ SYBR Green PCR buffer (Applied Biosystems), $0.1 \mathrm{U} / \mu \mathrm{l}$ AmpliTaq Gold DNA Polymerase (Applied Biosystems), $0.01 \mathrm{U} / \mu \mathrm{l}$ Amp Erase (Applied Biosystems), RNase-free water, and $2 \mu \mathrm{cDNA}$ samples. Thermal cycling conditions were optimized for each primer pair using standard conditions and varying annealing temperatures as suggested by Primer3. To verify the absence of nonspecific products, we performed 80 cycles of melting $\left(55^{\circ} \mathrm{C}\right.$ for 10 seconds). In all cases, the melting curve confirmed that a single product was generated. Amplification was monitored by measuring the increase in fluorescence caused by the binding of SYBR Green to doublestranded DNA. Fluorescent threshold values were measured in triplicate, and

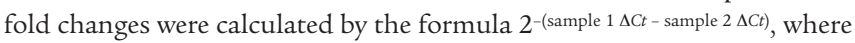
$\Delta C t$ is the difference between the amplification fluorescence thresholds of the mRNA of interest and the $\beta$-actin mRNA. We performed Q-RT-PCR for CXCL1 and CXCL10 using the predeveloped TaqMan assay reagent kit (Assay on Demand; Applied Biosystems).

Oligonucleotide DNA microarray. The detailed protocol for the microarray hybridizations, sample preparation, and the Rat Genome U34 Set are available from Affymetrix. Briefly, $10 \mu \mathrm{g}$ purified total RNA was transcribed into a first cDNA using Superscript RT (Invitrogen Corp.), in the presence of T7-oligo(dT) 24 primer, dNTPs, and T7 RNA polymerase promoter (Invitrogen Corp.). The double-stranded cDNA was cleaned, and an in vitro transcription reaction was then performed to generate biotinylated CRNA, which, after fragmentation, was used in a hybridization assay on RG-U34A and RG-U34B GeneChip microarrays. The A array contains probes representing full-length or annotated genes as well as EST clusters. The B array contains only EST clusters. Before hybridization, we estimated the efficiency of cDNA synthesis by calculating, in a test chip, the ratios for $5^{\prime}$ and middle intensities relative to $3^{\prime}$ for the control genes actin and GAPDH. Biotinylated RNA used as a target in the microarray hybridization was stained with a streptavidin-phycoerythrin conjugation including an amplification step with a secondary antibody and scanned in a confocal laser-scanning microscope (GeneArray Scanner G2500A; Hewlett Packard). Normalization was performed by global scaling, with the arrays scaled to an average intensity of 150 . We performed analysis of differential expression using Microarray Suite software 5.0 (Affymetrix). The final results were imported into Microsoft Excel (version 11.1; Microsoft).

Protein studies. Protein extractions and immunoblotting experiments were performed according to standard procedures. Briefly, cells were harvested in lysis buffer (50 mM HEPES, pH 7.5, $150 \mathrm{mM} \mathrm{NaCl}, 10 \%$ glycerol, 1\% Triton X-100, 1 mM EGTA, $1.5 \mathrm{mM} \mathrm{MgCl} 2,10 \mathrm{mM} \mathrm{NaF}, 10 \mathrm{mM}$ sodium pyrophosphate, $1 \mathrm{mM} \mathrm{Na} 3 \mathrm{VO}_{4}, 10 \mu \mathrm{g}$ aprotinin/ml, $10 \mu \mathrm{g}$ leupeptin/ml) and clarified by centrifugation at $10,000 \mathrm{~g}$. Protein concentration was estimated with a modified Bradford assay (Bio-Rad Laboratories). Immune complexes were detected with the enhanced chemiluminescence kit (ECL; Amersham Biosciences). Signal intensity was analyzed with Phosphorimager (Typhoon 8600; Amersham Biosciences) interfaced with ImageQuant software (version 5.0; Amersham Biosciences). Anti-RET is an affinity-purified polyclonal antibody raised against the tyrosine kinase protein fragment of human RET. Anti-ERK (no. 9101) and anti-phospho-ERK (no. 9102) were from Cell Signaling Technology. Anti-myc antibody and antibodies 
against cyclin D1, BRAF, and c-RAF were from Santa Cruz Biotechnology Inc. Anti-RAS and anti-phosphotyrosine antibodies were from Upstate Biotechnology Inc. Anti-AKT and anti-phospho-AKT, specific for the active AKT phosphorylated at serine 473, were from Cell Signaling Technology. Monoclonal anti- $\alpha$-tubulin was from Sigma-Aldrich. Secondary antibodies coupled to HRP were from Amersham Biosciences. For the BRAF kinase assay, cells were cultured for 12 hours in serum-deprived medium and harvested. BRAF kinase was immunoprecipitated with the anti-myc epitope antibody and resuspended in a kinase buffer containing $25 \mathrm{mM}$ sodium pyrophosphate, $10 \mu \mathrm{Ci}\left[{ }^{32} \mathrm{P}\right] \mathrm{ATP}$, and $1 \mu \mathrm{g}$ recombinant glutathione-Stransferase-MEK (GST-MEK; Upstate Biotechnology Inc.). After 30 minutes incubation at $4{ }^{\circ} \mathrm{C}$, reactions were stopped by adding $2 \times$ Laemmli buffer. Proteins were then subjected to $12 \%$ SDS gel electrophoresis. The radioactive signal was analyzed with the Phosphorimager.

ELISA assay. Thyroid cells plated in 6-well dishes were allowed to grow to $70 \%$ confluency and then serum deprived for 24 hours. The culture medium was cleared by centrifugation at $800 \mathrm{~g}$ at $4^{\circ} \mathrm{C}$ to remove detached cells and debris. We measured CXCL1 and CXCL10 levels in culture supernatants using a quantitative immunoassay ELISA kit (QuantiKine ELISA kit; R\&D Systems), following the manufacturer's instructions. For chemokine detection in TPC1 BRAF-depleted cells, supernatants were harvested 96 hours after siRNA transfection. Cells were serum starved for 4 hours before harvesting. Samples prepared in triplicate were analyzed at $490 \mathrm{nM}$ with an ELISA reader (model 550 microplate reader; Bio-Rad Laboratories).

Flow cytometric analysis. Subconfluent TPC1 cells were detached from culture dishes with a solution of $0.5 \mathrm{mM}$ EDTA and then washed 3 times in PBS buffer. After saturation with $1 \mu \mathrm{g}$ of human $\mathrm{IgG} / 10^{5}$ cells, cells were incubated for 20 minutes on ice with fluorescein- or phycoerythrin-labeled antibodies specific for human CXCR2 or CXCR3 (R\&D Systems) or isotype control antibody. After incubation, we removed unreacted antibody by washing cells twice in PBS buffer. Cells resuspended in PBS were analyzed on a FACSCalibur automated cell analysis system using CellQuest version 3.3 software (BD). Analyses were performed in triplicate. In each analysis, a total of $10^{4}$ events was calculated.

Matrigel invasion. In vitro invasiveness through Matrigel was assayed using transwell cell culture chambers according to previously described procedures (51). Briefly, confluent cell monolayers were harvested with trypsin/ EDTA and centrifuged at $800 \mathrm{~g}$ for 10 minutes. The cell suspension $\left(1 \times 10^{5}\right.$ cells/well) was added to the upper chamber of a prehydrated polycarbonate membrane filter of $8-\mu \mathrm{M}$ pore size (Costar; Corning) coated with $35 \mu \mathrm{g}$ Matrigel (Collaborative Research Inc.). The lower chamber was filled with complete medium and, when required, purified CXCL1 or 10 (PeproTech), at a concentration of $100 \mathrm{ng} / \mathrm{ml}$, was added to the lower chamber. When required, the cells were pretreated for 12 hours with U0126 $(20 \mu \mathrm{M})$ or for 20 minutes with CXCL1, CXCL10, CXCR2, and CXCR3 blocking antibodies $(1 \mu \mathrm{g} / \mathrm{ml}$; R\&D Systems), PTX $(0.1 \mu \mathrm{g} / \mathrm{ml}$; Calbiochem), or the blocking compounds SB225002 (10 nM; Calbiochem) and TAK-779 (100 nM). The latter reagent was obtained from the NIH AIDS Research and Reference Reagent Program, Division of AIDS, National Institute of Allergy and
Infectious Diseases. Where indicated, PC RET/PTC3 and TPC1 cells were transfected with BRAF siRNA, harvested at 48 and 72 hours, respectively, and plated on Matrigel. Cells were then incubated at $37^{\circ} \mathrm{C}$ in a humidified incubator in $5 \% \mathrm{CO}_{2}$ and $95 \%$ air for 24 hours. Nonmigrating cells on the upper side of the filter and Matrigel were wiped off, and migrating cells on the reverse side of the filter were stained with $0.1 \%$ crystal violet in $20 \%$ methanol for 15 minutes and photographed. The stained cells were lysed in 10\% acetic acid. Triplicate samples were analyzed at $570 \mathrm{nM}$ with an ELISA reader (model 550 microplate reader). The results were expressed as percentage of migrating cells to PC RET/PTC3- or chemokine-stimulated TPC1 cells.

S-phase entry. S-phase entry was evaluated by BrdU incorporation and indirect immunofluorescence. Cells were grown on coverslips and serum deprived for 30 hours. When indicated, cells were treated with CXCL1 or CXCL10 (PeproTech), at a concentration of $500 \mathrm{ng} / \mathrm{ml}$, for 30 hours. When required, the cells were treated for 24 hours with CXCL1, CXCL10, CXCR2, and CXCR3 blocking antibodies ( $1 \mu \mathrm{g} / \mathrm{ml}$; R\&D Systems), PTX (0.1 $\mu \mathrm{g} / \mathrm{ml}$; Calbiochem), or the blocking compounds SB225002 (10 nM; Calbiochem) and TAK-779 $(100 \mathrm{nM})$. BrdU was added at a concentration of $10 \mu \mathrm{M}$ for the last 2 hours. Subsequently, cells were fixed in $3 \%$ paraformaldehyde and permeabilized with $0.2 \%$ Triton X-100. BrdU-positive cells were revealed with Texas red-conjugated secondary antibodies (Jackson ImmunoResearch Laboratories Inc.). Cell nuclei were identified by Hoechst staining. Fluorescence was visualized with a Zeiss 140 epifluorescence microscope (Carl Zeiss International).

Statistical analysis. Significance was determined by the Mann-Whitney $U$ test using STATSOFT version 6.0 software. $P$ values less than 0.05 were considered statistically significant.

\section{Acknowledgments}

We are grateful to C.J. Marshall for the BRAF expression plasmid; to F. Curcio for the P5 primary thyroid culture; to J.M. Hershman for the BHP2-7 and BHP5-16 cell lines; and to L. Vitiello and L. Racioppi for FACS analysis of thyroid cell cultures. We would like to thank J. Gilder for editing the text. This study was supported by the Associazione Italiana per la Ricerca sul Cancro (AIRC), the Progetto Strategico Oncologia of the CNR/Italian Ministero per l'Istruzione, Università e Ricerca Scientifica (MIUR), Biotecnologia e Genetica Molecolare nel Mezzogiorno d'Italia (BioGeM) s.c.ar.l., the Italian Ministero della Salute, and the Centro Regionale di Competenza GEAR (Genomic for Applied Research). V. Guarino and M.D. Castellone were recipients of BioGeM s.c.ar.l. fellowships.

Received for publication July 19, 2004, and accepted in revised form January 25, 2005.

Address correspondence to: Massimo Santoro, Dipartimento di Biologia e Patologia Cellulare e Molecolare, via S. Pansini 5, 80131 Naples, Italy. Phone: 39-081-7463056; Fax: 39-081-7463037; E-mail: masantor@unina.it.
1. Rosai, J., Carcangiu, M.L., and DeLellis, R.A. 1992 Atlas of tumor pathology: tumors of the thyroid gland. 3rd series. Armed Forces Institute of Pathology. Washington, D.C., USA. 343 pp.

2. Manie, S., Santoro, M., Fusco, A., and Billaud, M. 2001. The RET receptor: function in development and dysfunction in congenital malformation. Trends Genet. 17:580-589.

3. Santoro, M., et al. 1992. Ret oncogene activation in human thyroid neoplasms is restricted to the papillary cancer subtype. J. Clin. Invest. 89:1517-1522.

4. Fagin, J.A. 2002. Perspective: lessons learned from molecular genetic studies of thyroid cancer-- insights into pathogenesis and tumor-specific therapeutic targets. Endocrinology. 143:2025-2028.

5. Santoro, M., et al. 1996. Development of thyroid papillary carcinomas secondary to tissue-specific expression of the RET/PTC1 oncogene in transgenic mice. Oncogene. 12:1821-1826.

6. Buckwalter, T.L., et al. 2002. The roles of phosphotyrosines-294, -404, and -451 in RET/PTC1induced thyroid tumor formation. Oncogene. 21:8166-8172.

7. Fusco, A., et al. 2002. Assessment of RET/PTC oncogene activation and clonality in thyroid nodules with incomplete morphological evi- dence of papillary carcinoma: a search for the early precursors of papillary cancer. Am.J. Pathol. 160:2157-2167.

8. Pierotti, M.A. 2001. Chromosomal rearrangements in thyroid carcinomas: a recombination or death dilemma. Cancer Lett. 166:1-7.

9. Zhu, Z., Gandhi, M., Nikiforova, M.N., Fischer, A.H., and Nikiforov, Y.E. 2003. Molecular profile and clinical-pathologic features of the follicular variant of papillary thyroid carcinoma. An unusually high prevalence of ras mutations. Am.J. Clin. Pathol. 120:71-77.

10. Kimura, E.T., et al. 2003. High prevalence of braf 
mutations in thyroid cancer: genetic evidence for constitutive activation of the RET/PTC-RAS-BRAF signaling pathway in papillary thyroid carcinoma. Cancer Res. 63:1454-1457.

11. Malumbres, M., and Barbacid, M. 2003. RAS oncogenes: the first 30 years. Nat. Rev. Cancer. 3:459-465.

12. Davies, H., et al. 2002. Mutations of the BRAF gene in human cancer. Nature. 417:949-954.

13. Cohen, Y., et al. 2003. BRAF mutation in papillary thyroid carcinoma. J. Natl. Cancer Inst. 95:625-627.

14. Soares, P., et al. 2003. BRAF mutations and RET/ PTC rearrangements are alternative events in the etiopathogenesis of PTC. Oncogene. 22:4578-4580.

15. Fagin, J.A. 2004. How thyroid tumors start and why it matters: kinase mutants as targets for solid cancer pharmacotherapy. J. Endocrinol. 183:249-256.

16. Schlessinger, J., and Lemmon, M.A. 2003. SH2 and PTB domains in tyrosine kinase signaling [review]. Sci. STKE. 191:RE12.

17. Kawamoto, Y., et al. 2004. Identification of RET autophosphorylation sites by mass spectrometry. J. Biol. Chem. 279:14213-14224.

18. Pandey, A., et al. 1996. Direct association between the Ret receptor tyrosine kinase and the Src homology 2-containing adapter protein Grb7. J. Biol. Chem. 271:10607-10610.

19. Borrello, M.G., et al. 1996. The full oncogenic activity of Ret/ptc2 depends on tyrosine 539, a docking site for phospholipase Cgamma. Mol. Cell. Biol. 16:2151-2163.

20. Encinas, M., Crowder, R.J., Milbrandt, J., and Johnson, E.M., Jr. 2004. Tyrosine 981, a novel Ret autophosphorylation site, binds c-Src to mediate neuronal survival. J. Biol. Chem. 279:18262-18269.

21. Ichihara, M., Murakumo, Y., and Takahashi, M. 2004. RET and neuroendocrine tumors. Cancer Lett. 204:197-211.

22. Melillo, R.M., et al. 2001. Docking protein FRS2 links the protein tyrosine kinase RET and its oncogenic forms with the mitogen-activated protein kinase signaling cascade. Mol. Cell. Biol. 21:4177-4187.

23. Castellone, M.D., et al. 2003. Ras-mediated apoptosis of PC CL 3 rat thyroid cells induced by RET/PTC oncogenes. Oncogene. 22:246-255.

24. Fusco, A., et al. 1987. One- and two-step transformations of rat thyroid epithelial cells by retroviral oncogenes. Mol. Cell. Biol. 9:3365-3370.

25. Santoro, M., et al. 1993. The TRK and RET tyrosine kinase oncogenes cooperate with ras in the neo- plastic transformation of a rat thyroid epithelial cell line. Cell Growth Differ. 4:77-84.

26. Knauf, J.A., Kuroda, H., Basu, S., and Fagin, J.A. 2003. RET/PTC-induced dedifferentiation of thyroid cells is mediated through Y1062 signaling through SHC-RAS-MAP kinase. Oncogene. 22:4406-4412.

27. Shirokawa, J.M., et al. 2000. Conditional apoptosis induced by oncogenic ras in thyroid cells. Mol. Endocrinol. 14:1725-1738.

28. Nikiforova, M.N., et al. 2003. BRAF mutations in thyroid tumors are restricted to papillary carcinomas and anaplastic or poorly differentiated carcinomas arising from papillary carcinomas. J. Clin. Endocrinol. Metab. 88:5399-5404.

29. Dhawan, P., and Richmond, A. 2002. Role of CXCL1 in tumorigenesis of melanoma. J. Leukoc. Biol. 72:9-18.

30. Luster, A.D. 1998. Chemokines--chemotactic cytokines that mediate inflammation. N. Engl.J. Med. 338:436-445.

31. Mellado, M., Rodriguez-Frade, J.M., Manes, S., and Martinez-A, C. 2001. Chemokine signaling and functional responses: the role of receptor dimerization and TK pathway activation. Annu. Rev. Immunol. 19:397-421.

32. Scarpino, S., et al. 2000. Papillary carcinoma of the thyroid: hepatocyte growth factor (HGF) stimulates tumor cells to release chemokines active in recruiting dendritic cells. Am.J. Pathol. 156:831-837.

33. White, J.R., et al. 1998. Identification of a potent, selective non-peptide CXCR2 antagonist that inhibits interleukin-8-induced neutrophil migration. J. Biol. Chem. 273:10095-10098.

34. Gao, P., et al. 2003. The unique target specificity of a nonpeptide chemokine receptor antagonist: selective blockade of two Th1 chemokine receptors CCR5 and CXCR3. J. Leukoc. Biol. 73:273-280.

35. Eblaghie, M.C., et al. 2003. Negative feedback regulation of FGF signaling levels by Pyst1/MKP3 in chick embryos. Curr. Biol. 13:1009-1018.

36. Carlomagno, F., et al. 2002. ZD6474, an orally available inhibitor of KDR tyrosine kinase activity, efficiently blocks oncogenic RET kinases. Cancer Res. 62:7284-7290.

37. Lyons, J.F., Wilhelm, S., Hibner, B., and Bollag, G. 2001. Discovery of a novel Raf kinase inhibitor. Endocr. Relat. Cancer. 8:219-225.

38. Liotta, L.A., and Kohn, E.C. 2001. The microenvironment of the tumour-host interface.
Nature. 411:375-379.

39. Dahlman, T., et al. 2002. Collagen type I expression in experimental anaplastic thyroid carcinoma: regulation and relevance for tumorigenicity. Int.J. Cancer. 98:186-192.

40. Califano, D., et al. 1998. Thymosin beta-10 gene overexpression correlated with the highly malignant neoplastic phenotype of transformed thyroid cells in vivo and in vitro. Cancer Res. 58:823-828.

41. Huang, Y., et al. 2001. Gene expression in papillary thyroid carcinoma reveals highly consistent profiles. Proc. Natl. Acad. Sci. U. S. A 98:15044-15049.

42. Bartolazzi, A., et al. 2001. Application of an immunodiagnostic method for improving preoperative diagnosis of nodular thyroid lesions. Lancet. 357:1644-1650.

43. El-Rifai, W., et al. 2002. Gastric cancers overexpress S100A calcium-binding proteins. Cancer Res. 62:6823-6826.

44. Elsalini, O.A., von Gartzen, J., Cramer, M., and Rohr, K.B. 2003. Zebrafish hhex, nk2.1a, and pax2.1 regulate thyroid growth and differentiation downstream of Nodal-dependent transcription factors. Dev. Biol. 263:67-80.

45. Hackel, P.O., Gishizky, M., and Ullrich, A. 2001. Mig- 6 is a negative regulator of the epidermal growth factor receptor signal. Biol. Chem. 382:1649-1662.

46. Balkwill, F., and Mantovani, A. 2001. Inflammation and cancer: back to Virchow? Lancet. 357:539-545.

47. Coussens, L.M., and Werb, Z. 2002. Inflammation and cancer. Nature. 420:860-867.

48. Curcio, F., Ambesi-Impiombato, F.S., Perrella, G., and Coon, H.G. 1994. Long-term culture and functional characterization of follicular cells from adult normal human thyroids. Proc. Natl. Acad. Sci.U.S. A. 91:9004-9008.

49. Hingorani, S.R., Jacobetz, M.A., Robertson, G.P., Herlyn, M., and Tuveson, D.A. 2003. Suppression of BRAF(V599E) in human melanoma abrogates transformation. Cancer Res. 63:5198-5202.

50. Yuan, B., Latek, R., Hossbach, M., Tuschl, T., and Lewitter, F. 2004. siRNA Selection Server: an automated siRNA oligonucleotide prediction server. Nucleic Acids. Res. 32:W130-W134.

51. Castellone, M.D., et al. 2004. Autocrine stimulation by osteopontin plays a pivotal role in the expression of the mitogenic and invasive phenotype of RET/PTC-transformed thyroid cells. Oncogene. 23:2188-2196. 